\title{
COMPETENCIAS PROFESIONALES Y LA EMPLEABILIDAD, PARA EGRESADOS $Y$ TITULADOS DE LA CARRERA DE AUDITORÍA.
}

\author{
PROFESSIONAL SKILLS RELATED TO \\ EMPLOYABILITY FOR GRADUATES CAREER \\ AUDIT.
}

\author{
Emilio Enrique González Díaz ${ }^{1}$ y Mauricio Iván Alfaro Castillo
}

\section{RESUMEN}

Entre los objetivos formulados en la declaración de Bolonia (1999), y que son el eje sobre el que se sustenta el nuevo paradigma educativo en la educación superior, se encuentra: "Formular criterios académicos, competenciales y de cualificación profesional que respondan a la demanda del mercado laboral y que permitan responder a los retos educativo, laborales y sociales actuales". La Conferencia de Berlín (2003), pone énfasis en la empleabilidad de los graduados, La Conferencia de Bergen (2005), señala que para mejorar el empleo de los graduados, es necesario reforzar el diálogo con Empleadores y Agentes sociales.

A raíz de los constantes cambios generados en la profesión y la necesidad de adecuarse a ellos permanentemente, se hace necesaria una evaluación constante de las capacidades y conocimientos de los profesionales del área de la auditoría. La presente investigación realiza un análisis de la valoración de las demandas de mercado, de las competencias profesionales para la inserción laboral y remuneración de los titulados de la carrera de Auditoría en la Ciudad de La Serena, con el objetivo de entregar información actualizada de los factores de empleabilidad, como insumo útil, para la orientación de los planes y programas de estudios, movilizando el capital intelectual y alineándolo a lo demandado por los agentes socioeconómicos.

El estudio se configuró una perspectiva mixta., El rasgo cualitativo se manifiesta en la obtención de información de los egresados de carreras de auditoría, considerados como agentes estratégicos mediante las percepciones y visiones subjetivas que estos entregan, mientras que lo cuantitativo se expresa en función del análisis de datos obtenidos en la aplicación de la encuesta de inserción de l'Agència per a la Qualitat del Sistema Universitari de Catalunya (AQU).

La investigación permitió identificar las competencias profesionales más valoradas en el mercado para los Contadores Auditores recientemente egresados, así como, confirmar la importancia de las características personales, como factor determinante en la empleabilidad. Se determinó que los egresados establecían una relación entre competencias, rubro de desempeño y el nivel de remuneraciones, así como una valoración de la calidad del trabajo.

Palabras claves: Competencias Profesionales, Empleabilidad, Inserción Laboral.

Recepción: 17/06/2016. Aprobación: 26/09//2016.

1 Departamento de Ciencias Económicas y Empresariales, Facultad de Ciencias Sociales y Económicas, Universidad de La Serena, La Serena, Chile, eegonzalez@userena.cl

2 Departamento de Ciencias Económicas y Empresariales, Facultad de Ciencias Sociales y Económicas, Universidad de La Serena, La Serena, Chile, malfaroc@userena.cl 


\section{ABSTRACT}

Among the objectives formulated in the Bologna Declaration (1999), and in this case, been axis on which the new educational paradigm in higher education is based, it is: "Develop academic, competence and professional qualification criteria to answer the labor market demand the and let respond to the current educational, labor and social challenges". The Berlin Conference (2003), emphasizes the employability of graduates. The Bergen Conference (2005), points out that to improve the employability of graduates, it is necessary to strengthen the dialogue between employers and social agents.

Following the constant changes generated in the profession and the need to adapt to them permanently constant evaluation of the skills and knowledge of professionals in the area of the audit is necessary. This research makes an analysis of the evaluation of the demands of market, professional skills for employment and remuneration of the graduates from the Accountancy program in the city of La Serena, in order to provide updated information on employability factors, as useful input to the orientation of the study programs, mobilizing the brainpower and aligning it to what socio-economic actors demand.

The study sets a mixed perspective. The qualitative trait manifests by obtaining information of the graduates of audit considered like strategic actors, in this case graduates by subjective perceptions and visions that those delivered, while the quantity is expressed in terms of the analysis of data obtained by implementing an insertion surveym l'Agència per a la Qualitat from the System of University of Catalonia (AQU).

The investigation allowed to identify the most valued skills according to the market for recent graduates of Accountancy, and provide the confirmation of the importance of personal characteristics, as a factor in employability. It was determined the existence of a relationship between skills, performance category and level of remuneration, same as the determination of the assessing on quality of work.

Keywords: Employability, Job Placement, Professional skills.

\section{INTRODUCCIÓN}

En un entorno global y competitivo, cada vez más demandante de prácticas eficientes, como actual, surge la necesidad de contar con profesionales capaces de responder a requerimientos de control y revisión continua de procesos y actividades que se ejecutan en los diversas tipos empresas y organizaciones, tanto privadas como gubernamentales.

En las últimas décadas la marcada y constante evolución de la auditoría ha provocado que el auditor no se desempeñe como profesional con un enfoque holístico sino más bien se ha marcado la especialización de este tanto en los aspectos personales, como el las competencias profesionales (Marques 2001).

El profesional de la auditoría desde sus orígenes ha sido vinculado casi en exclusividad a desempeñarse en lo relacionado a preparación, análisis, revisión y validación de estados financieros, de hecho en los orígenes de la profesión se limitaba a la mera vigilancia con la finalidad de evitar fraudes y errores. Luego con el crecimiento de las empresas y la separación de la propiedad de la administración, se hizo necesario garantizar (Marques 2001), la información económica financiera de las organizaciones. En Gran Bretaña, debido a las quiebras que se produjeron durante la revolución industrial, se desarrolló la auditoría para generar confianza en los inversores, cuestión que no tardó en extenderse a otros países. Posteriormente las crisis de Wall Strett de 1929 y las sucesivas crisis hasta hoy, han fortalecido a la profesión tanto del punto de vista ético, técnico, legislativo y de investigación.

De acuerdo al enfoque anterior, los cambios que ha experimentado y sigue experimentando el profesional de la auditoría, lo ha llevado a desempeñarse en distintas áreas, lo que genera diferencias socio-laborales, expresadas en empleabilidad, calidad de empleo y remuneraciones.

La evidencia, demuestra que los profesionales de la Auditoría, egresados de Instituciones de educación superior de la comuna de La Serena, experimentan una significativa variabilidad en los aspectos antes señalado, lo cual hace necesario estudia las causales que generan estas 
diferencias. De esta manera surgen las siguientes interrogantes:

- ¿Existen diferencias en la calidad de empleo y las remuneraciones de los egresados de la carrera de auditoría, en función del área de desempeño en la que se desenvuelven?

- ¿Las competencias profesionales del egresado de carreras de auditoría de la ciudad de La Serena, condicionan la calidad de empleo y su remuneración?

\section{Objetivo general}

Analizar la Valoración a las demandas de mercado, de las competencias profesionales para la inserción laboral y remuneración de los titulados de la carrera de auditoría, en la actualidad para la comuna de La Serena.

\section{Objetivos específicos}

- Analizar situación socio-laboral de los egresados de carreras de Auditoría

- Identificar competencias profesionales requeridas para el egresado de las carreras de Auditoría en la actualidad,

- Describir la relación entre competencias profesionales, empleabilidad y remuneración, a través de relación causa efecto.

\section{Hipótesis}

$\mathrm{H}_{\mathrm{A}}$ : La empleabilidad, remuneraciones y calidad de empleo de los egresados de la carrera de $\mathrm{Au}$ ditoría, está determinada por las competencias profesionales que posea el egresado.

\section{Metodología}

La metodología de la investigación ha sido por siempre el sustento empírico de todo estudio. El cómo se llevará a cabo la investigación y el perfil al que esta responde, son aspectos relevantes de considerar. Tomando en consideración lo anterior, es posible señalar que el presente estudio se enmarca dentro de un diseño no experimental, puesto que se estudia el fenómeno bajo sus condiciones naturales y no se realiza manipulación de las variables, ya que al hacerlo se estarían sesgando los datos al momento de analizarlos.

Con respecto al enfoque, el estudio configura una perspectiva mixta (Hernández 2003). Perspectiva en que se fusionan elementos tanto del área cualitativa como cuantitativa. El rasgo cua- litativo se manifiesta en la obtención de información de agentes estratégicos, en este caso los egresados, mediante las percepciones y visiones subjetivas que estos nos entregan, mientras que lo cuantitativo se expresa en función del análisis de los datos obtenidos en el instrumento aplicado.

Con respecto al tipo de investigación, la metodología utilizada fue inicialmente de carácter exploratorio, para continuar con un estudio de tipo descriptivo. En primer lugar se identifica las competencias profesionales requeridas por el mercado, para el egresado de las carreras de $\mathrm{Au}$ ditoría en la actualidad, en base a información bibliográfica y documental. En segundo lugar se analizó la situación socio laboral de los egresados de las carreras de Auditoría, de instituciones de educación superior de la ciudad de La Serena, analizando aspectos tales como: La situación laboral actual, el acceso al primer empleo, la satisfacción con el trabajo actual, la valoración de los factores de contratación, la remuneración obtenida, la adecuación de la formación recibida al empleo ocupado, la formación continuada, la movilidad, el rendimiento académico y status económico, así como, las acciones emprendidas en caso de estar actualmente desempleado. Para ello se aplicó, como base, entre enero y mayo del año 2015 la encuesta de inserción de l'Agència per a la Qualitat del Sistema Universitari de Catalunya (AQU 2008) por tratarse de un instrumento estadísticamente y sociológicamente validado y utilizado en un estudio similar llamado "Competencias profesionales y empleabilidad: la inserción laboral de los licenciados en publicidad y RR.PP. de la Universitat Abat Oliba Ceu", de las autores Lasaga y Barraycoa 2010.

Siguiendo el esquema de Kinnear y Taylor (1993), los pasos para definir la muestra fueron los siguientes:

\section{a. Población:}

i. Alcance: Instituciones de Educación superior de la Ciudad de La Serena, que cuenten con egresados durante los 4 últimos años.

ii. Tiempo: egresados entre 2011 y 2014.

iii. Elementos: Egresados de instituciones de educación superior de la carrera de Auditoría.

iv. Unidades de muestreo: Todos los egresados de instituciones de educación superior de la carrera de Auditoría, alcanzan un total 324 egresados. 
a. Marco muestral: En concordancia con las restricciones establecidas para la población, los sujetos objeto de estudio, pertenecen solamente a la Universidad de La Serena y a Inacap.

b. Tamaño de la muestra: El estudio se aplicó a 158 egresados de las instituciones señaladas.

c. Procedimiento de muestreo: Se utilizó un muestreo no probabilístico por conveniencia, en función de la accesibilidad de los sujetos para los investigadores.

El trabajo de campo se desarrolló considerando como fuente de información primaria, la aplicación de la encuesta, esta se aplicó a los sujetos de la muestra, en formato papel, así como en formato digital a través de un portal en internet. Como fuente secundaria se utilizó bibliografía relacionada con empleabilidad y competencias, así como las declaraciones y escritos emanados en conferencias como la de Bolonia (1999), la Conferencia de Berlín (2003), la Conferencia de Bergen (2005), entre otros. El procesamiento y análisis de resultados se realizó utilizando herramientas como el diagrama causa efecto, así como el uso de software para determinación de tendencia central y dispersión.

\section{Exposición de Resultados:}

Entre Enero y Mayo del año 2015 se aplicó una encuesta a 158 egresados, entre los años 2011 y 2014, de las carreras de auditoría de la Universidad de La Serena y de INACAP, por ser los programas cumplen con la restricción de tener egresados en los 4 últimos años. En esta encuesta de consultó sobre la situación laboral actual, el acceso al primer empleo, la satisfacción con el trabajo actual, la valoración de los factores de contratación, la remuneración obtenida, la adecuación de la formación recibida al empleo ocupado, la formación continuada, la movilidad, el rendimiento académico, el status económico y acciones emprendidas en caso de estar titulado.

Una vez obtenidos los resultados se procedió a su procesamiento y análisis, utilizando herramientas de análisis, como el diagrama causa efecto y software para determinación de tendencias. Obteniendo los siguientes resultados.

\section{Valoración de los factores de Contratación.}

La selección de personal en las empresas es una variable esencial para valorar la incidencia de la formación en competencias en la inserción laboral. Por lo cual se solicitó a los encuestados una ponderación sobre los factores que han determinado su inserción laboral, Los resultados muestran que las competencias personales son las que tienen mayor valoración (Ver Gráfico 1) Destacando variables como "la manera de ser" y "la capacidad de trabajar en grupos", y sólo destaca una variable que no tiene que ver con la competencia personal que es "la formación Global en la Universidad". Se deduce entonces que la clave del éxito de un proceso de selección "radica en las competencias personales y sociales, tanto si se tienen como si se demuestra la capacidad para desarrollarlas". ${ }^{3}$

Por otra parte los conocimientos teóricos e instrumentales, alcanzan una puntuación baja, dada la percepción de los egresados que a medida que adquieren experiencia profesional lo teórico y lo instrumental se adquiere fácilmente. Además en esta carrera en particular el avance de las normas y la teoría es muy rápido, por lo cual una parte de la formación de hoy puede quedar obsoleta mañana. Por ello más que conocimientos teóricos, las empresas aprecian, como una cualidad personal importante, la capacidad de aprendizaje y adaptación.

3 BARRAYCOA MARTÍNEZ, J. y LASAGA MILLET, O., Competencias e inserción laboral: un análisis de la empleabilidad en los recién licenciados en Ade y Economía. Madrid: CEU Ediciones, 2009, pág. 134. 


\section{Gráfico 1: "VALORACIÓN DE LOS FACTORES DE CONTRATACIÓN"}

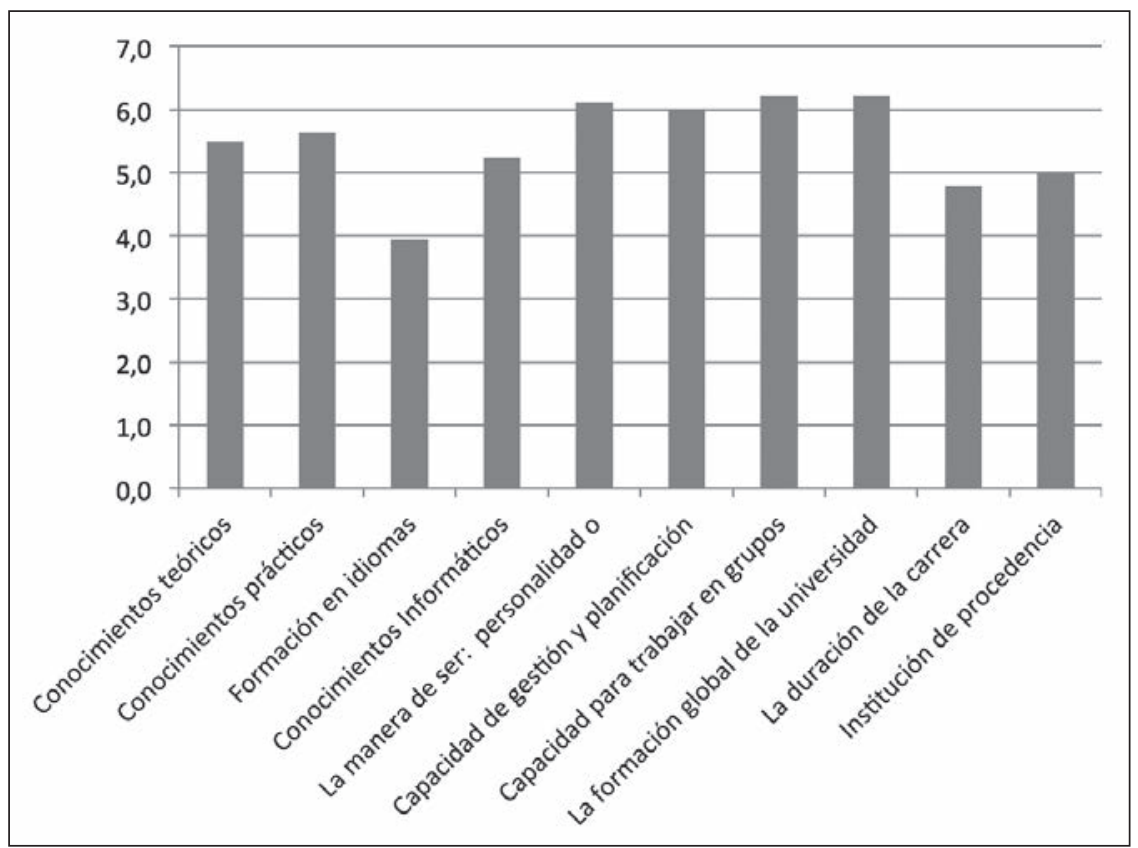

Fuente: Elaboración Propia año 2015.

2. Competencias Transversales: Comparativo entre los conocimientos adquiridos en la universidad $v / s$ su utilidad en el trabajo.

En la encuesta aplicada, se solicitó a los egresados que puntúen de 1 (muy bajo) a 7 (muy bueno) el nivel que adquirieron en la Universidad y su adecuación para el desempeño de su trabajo respecto a diversos aspectos relacionados tanto con la formación como con las competencias:

- Conocimientos teóricos

- Formación práctica

- Competencias instrumentales: informática e idiomas.

- Competencias sociales: trabajo en equipo y comunicación tanto oral como escrita.

- Competencias personales: liderazgo, gestión, resolución de problemas, toma de decisiones, creatividad y pensamiento crítico.
$\mathrm{Al}$ analizar la relación entre la formación en conocimientos y competencias adquirida a lo largo de los estudios de Contador Auditor. y su utilidad en el empleo, destaca que se mantienen las tendencias de opinión (véase gráfico 2). De todas formas se observa lo siguiente:

- La Valoración de las competencias es pareja, es decir no hay grandes diferencias de puntuación

- Las Competencias Instrumentales (Informática e idiomas), son las menos valoradas.

- Se han adquirido en el grado adecuado para el empleo: entre ellas están la expresión oral y escrita, el liderazgo, la resolución de problemas, la creatividad, el pensamiento crítico y los idiomas.

- La competencia social más valorada es el "trabajo en equipo".

- Y en las competencias personales destaca la "resolución de problemas"

- Además se valora más la competencia en la aplicación en el trabajo. 
Gráfico 2: “COMPARATIVA ENTRE EL NIVEL DE COMPETENCIAS ADQUIRIDO EN LA UNIVERSIDAD Y EL REQUERIDO PARA EL DESEMPEÑO DEL PUESTO DE TRABAJO”

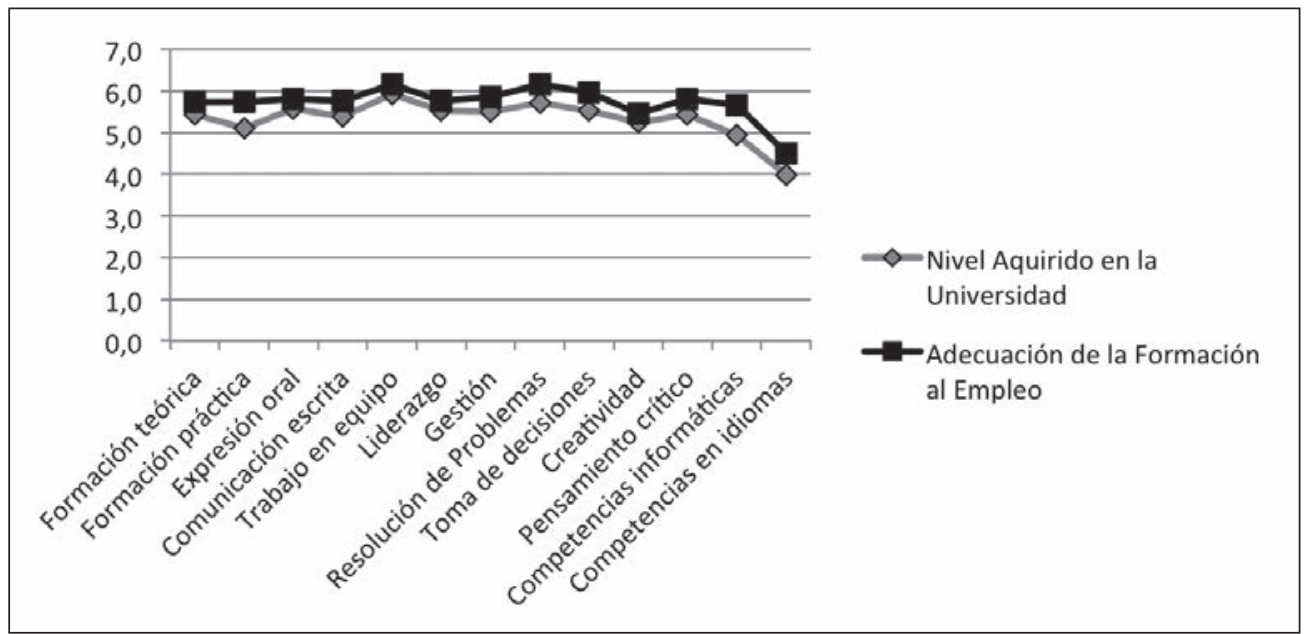

Fuente: Elaboración Propia año 2015.

\section{Sueldos.}

El sueldo bruto promedio en los egresados de la carrera de Auditoría entre los años 2011 y 2014 de la ciudad de La Serena es de \$714.768, registrándose el mayor sueldo por un monto bruto de $\$ 1.970 .000$ de un egresado que trabaja en el área de Recursos Humanos en el rubro de la minería, y el menor sueldo de $\$ 310.000$ corres- ponde a un egresado que trabaja como analista contable en una empresa de asesorías contables.

Se realizó un comparativo entre los sueldos brutos promedio según año de egreso y los datos entregados por el sitio Mi futuro.cl ${ }^{4}$, en el cual se puede ver que los egresados de la Ciudad de la Serena están por debajo de los promedios Nacionales

Tabla I: "COMPARATIVO ENTRE SUELDOS NACIONALES V/S CIUDAD DE LA SERENA"

\begin{tabular}{|l|c|c|}
\hline Años de Egreso & $\begin{array}{c}\text { Sueldo Promedio } \\
\text { según encuesta }\end{array}$ & $\begin{array}{c}\text { Sueldo } \\
\text { Promedio, según } \\
\text { mifuturo.cl }\end{array}$ \\
\hline Egresados 2011 & 984.152 & 1.132 .154 \\
\hline Egresados 2012 & 710.892 & 1.041 .866 \\
\hline Egresados 2013 & 634.926 & 941.312 \\
\hline Egresados 2014 & 596.152 & 855.901 \\
\hline
\end{tabular}

Fuente: Elaboración Propia, año 2015.

También se efectuó un análisis respecto de los sueldos según la actividad económica en la que desenvuelven los egresados (Ver tabla $\mathrm{N}^{\circ} 2$ ), en donde se observó que las actividades que en- tregan mejor remuneración son las "asesorías" y el sector de "la minería" y la remuneración más baja está en los "servicios contables". 
Tabla II: "REMUNERACIÓN SEGÚN ACTIVIDAD ECONÓMICA"

\begin{tabular}{|l|c|r|}
\hline \multicolumn{1}{|c|}{ Actividad Económica } & Sueldos Promedio & \multicolumn{1}{c|}{$\%$} \\
\hline Auditoría & 796.587 & $21 \%$ \\
\hline Servicios Contables & 493.467 & $14 \%$ \\
\hline Minería & 841.862 & $13 \%$ \\
\hline Inmobiliario & 622.113 & $5 \%$ \\
\hline Salud & 476.872 & $5 \%$ \\
\hline Servicio Público & 760.711 & $5 \%$ \\
\hline Asesorías & 1.031 .200 & $5 \%$ \\
\hline Portuaria & 672.500 & $4 \%$ \\
\hline Educación & 650.585 & $4 \%$ \\
\hline Otros & 688.844 & $27 \%$ \\
\hline
\end{tabular}

Fuente: Elaboración Propia año 2015.

En el análisis de las remuneraciones, se analizó también el nivel de sueldo de acuerdo al área de desempeño (Ver Tabla $N^{\circ} 3$ ), destacando las mayores remuneraciones en las áreas de "recursos humanos" y "Finanzas" y la con menor remuneración "Contabilidad".

Tabla III: “REMUNERACIÓN SEGÚN ÁREA DE DESEMPEÑO”

\begin{tabular}{|l|c|r|}
\hline \multicolumn{1}{|c|}{ Aréa de Desempeño } & Sueldos Promedio & \multicolumn{1}{c|}{$\%$} \\
\hline Administración & 731.400 & $9 \%$ \\
\hline Auditoría & 729.368 & $17 \%$ \\
\hline Contabilidad & 632.424 & $39 \%$ \\
\hline Control Interno & 690.926 & $5 \%$ \\
\hline Finanzas & 798.733 & $6 \%$ \\
\hline Recursos Humanos & 960.857 & $3 \%$ \\
\hline Tesorería & 428.121 & $10 \%$ \\
\hline Tributaria & 846.864 & \\
\hline
\end{tabular}

Fuente: Elaboración Propia, año 2015.

4. Valoración del Trabajo: Comparativo entre mejor remuneración y mejor trabajo

En la encuesta aplicada, se solicitó a los egresados que puntúen de 1 (muy bajo) a 7 (muy bueno) en cuanto a la opción de optar a una mejor remuneración $\mathrm{v} / \mathrm{s}$ obtener un mejor trabajo de acuerdo al área de especialización entre las que se consideraron las siguientes: Auditoría, Contabilidad Avanzada, Tributación, Recursos Humanos, Tecnologías de la Información, Finanzas, Costos, Administración y Gestión.
$\mathrm{Al}$ analizar la relación entre mejor remuneración y mejor trabaja al que opta el egresado de Contador Auditor., se puede observar que existe similares tendencias (véase gráfico 3 ). De todas formas se observa lo siguiente:

- Las áreas con mayor valoración son "Tributaria", "Contabilidad Avanzada" y "Auditoría"

- Las de menor valoración son "Recursos Humanos", "Tecnologías de Información" y "Costos". 


\section{Gráfico 3: “COMPARATIVA ENTRE OPCIÓN A MEJOR REMUNERACIÓN V/S MEJOR TRABAJO"}

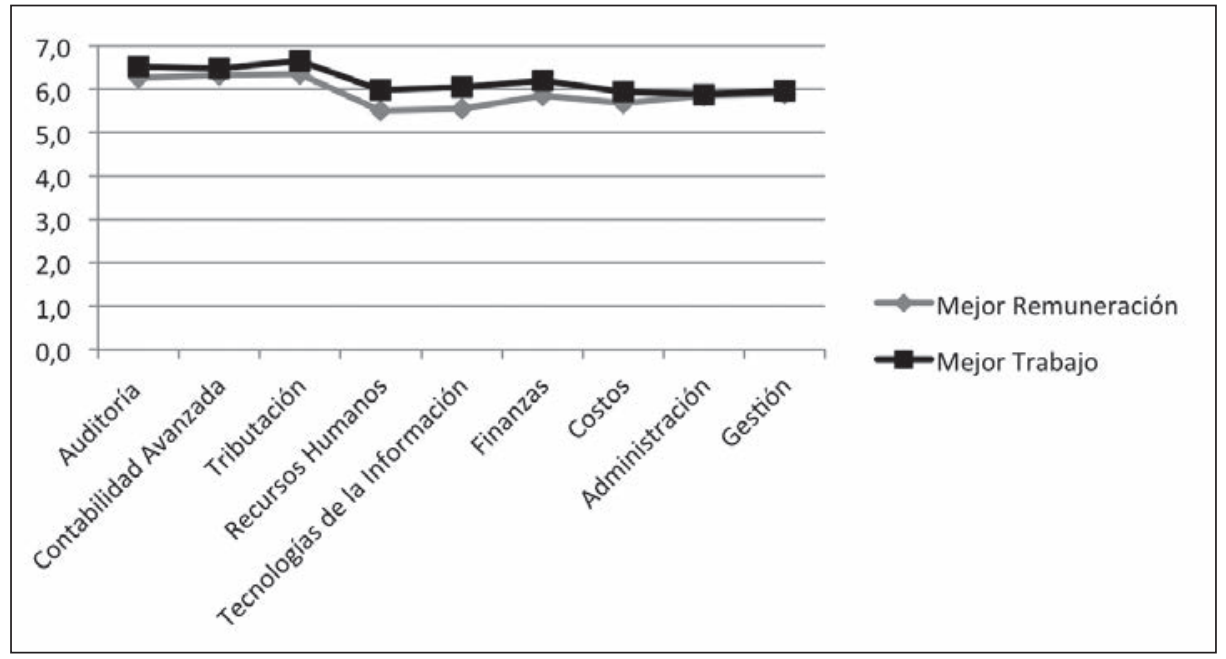

Fuente: Elaboración Propia, año 2015.

\section{Progresión Económica}

Se realizó una análisis respecto de la progresión socio económica de los alumnos identificando 2 variables: Primero el nivel socio económico en el que se clasifican y Segundo la progresión económica después de sus estudios. Respecto de la primera variable (Ver Tabla $\mathrm{N}^{\circ} 4$ ), se observa que el $90 \%$ de los egresados se clasifica en los estratos $\mathrm{C} 2$ y $\mathrm{C} 3$.

Tabla IV: “NIVEL SOCIO ECONÓMICO”

\begin{tabular}{|c|c|}
\hline Nivel Socio Económico & $\%$ \\
\hline ABC1 & $2 \%$ \\
\hline C2 & $45 \%$ \\
\hline C3 & $45 \%$ \\
\hline D & $7 \%$ \\
\hline E & $0 \%$ \\
\hline
\end{tabular}

Fuente: Elaboración Propia año 2015.

Respecto de la segunda variable, se observó que el $44 \%$ de los egresados mantenía el mismo Nivel Socio Económico, 47\% aumentaba un nivel y el 8\% aumentaba dos niveles, dándose sólo un $1 \%$ de retroceso de nivel socio económico.

\section{Desempleo}

Respecto de los egresados desempleados, estos representaron el $12 \%$ de la muestra. Las principales razones del desempleo fueron "Maternidad y Familia", "Continuidad de estudios", es decir más bien razones de población inactiva. A este grupo se les solicitó que valorarán con puntuación de 1 (nada de importante) a 7 (muy importante), las dificultades para encontrar empleo, lo cual arrojó los siguientes resultados (Ver Tabla N`5): 
Tabla V: “DIFICULTAD PARA ENCONTRAR EMPLEO”

\begin{tabular}{|l|c|}
\hline Dificultad & Nota \\
\hline Carencia en la formación universitaria recibida & 3,1 \\
\hline Actividades personales que te impiden trabajar & 3,9 \\
\hline Falta de práctica profesional & 2,9 \\
\hline Exigencia de tener un trabajo que me guste & 4,6 \\
\hline Falta de conocimiento del mercado laboral & 4,4 \\
\hline Exigencia de tener un trabajo bien remunerado & 4,6 \\
\hline Falta de conocimiento de idiomas & 3,1 \\
\hline Falta de conocimiento de Informática & 3,4 \\
\hline La formación global de la universidad & 3,8 \\
\hline
\end{tabular}

Fuente: Elaboración Propia, año 2015.

Como se puede observar las con mayor puntuación son las exigencias de tener un trabajo que me guste y bien remunerado, es decir un convencimiento personal más que razones de mercado.

\section{CONCLUSIÓN}

En esta investigación se pudo identificar cuáles son las competencias más valoradas en el mercado para los Contadores Auditores recientemente egresados, además se pudo analizar su nivel de remuneraciones y su valoración de la calidad del trabajo. Los resultados, evidencian que los egresados participan de la cultura de las competencias y son capaces de discriminar con un elevado grado de precisión el nivel de adquisición y dominio de las competencias sobre las que se les inquiere. Asimismo, tienen una capacidad crítica acerca de los desajustes entre su formación y las necesidades profesionales.

Cuando se aborda el estudio de las competencias desde la perspectiva de los empleadores o mediante el análisis de las ofertas de trabajo, se enriquece considerablemente la comprensión de las competencias. Realizar el esfuerzo de analizar las competencias de forma integral es indispensable, dada su importancia y correlación con la inserción laboral, como se ha detectado en el estudio piloto.

Los resultados obtenidos, permiten visualizar una valoración destacada, dentro de los factores de contratación a la formación global de la Universidad, así como, a la capacidad de trabajar en grupo.

En cuanto a la remuneración se evidenció para cada una de las cohortes estudiadas, valores descendidos respecto de la media nacional. Esta situación puede verse influida por el nivel socioeconómico inicial de los egresados y el ascenso evidenciado. Presentan niveles de ingresos, significativamente superiores, los obtenidos, en primer lugar, quienes se desempeñan realizando asesoría y en segundo lugar, aquellos que trabajan en empresas del rubro minero. Así mismo, se pudo observar, mayores ingresos obtenidos por quienes se desempeñan en el área de recursos humanos, seguido por tributaria y finanzas, siendo del área contable, quienes reciben las remuneraciones más bajas.

En lo referente a la percepción de calidad del trabajo, considerando aspectos, como horarios, ambiente laboral, capacidad de promoción, entre otros, se destaca, quienes trabajan en el área de la tributación y empresas auditoras.

La información presentada de los factores de empleabilidad, pueden transformarse un insumo útil, para la orientación de nuevos planes y programas de estudios, que estén acorde con las necesidades de mercado en función de la valoración otorgada, en coherencia con el paradigma actual de la educación superior.

En consideración a una de las funciones y obligaciones de las instituciones de educación superior, que es el la de preparar estudiantes para un mercado de trabajo específico, que requiere educación formal avanzada, con competencias y cualificación profesional para responder a las demandas presentadas y así conseguir mayor y mejor empleabilidad. Por consiguiente resulta necesario e indispensable, conocer dichas demandas, así como adaptarse a los nuevos requerimientos establecidos por los cambios 
frecuentes en los escenarios. Para los programas asociados a la auditoría, en la Comuna de la Serena, estos en la actualidad y de acuerdo a la percepción de profesionales egresados de éstas carreras, se debería fortalecer las áreas de Recursos Humanos, Finanzas, así como las competencias para el desarrollo de asistencia técnica y desempeño en sectores económicos específicos como minería y sector público, adicionales a las tradicionalmente fortalecidas, como contabilidad, tributaria y administración.

\section{BIBLIOGRAFIA}

Ayats, J.C. Zamora, P. Desantes, R., (2015) La Empleabilidad de los Titulados como Pilar Básico del Espacio Europeo de la Educación Superior, XIII CUIEET, Maspalomas (Gran Canaria).

Barraycoa Martínez, J. y Lasaga Millet, O., (2010), Competencias e inserción laboral: un análisis de la empleabilidad en los recién licenciados en Ade y Economía. Madrid: CEU Ediciones.

Ducci, María Angélica (1996). “El enfoque de competencia laboral en la perspectiva internacional", en Formación basada en competencia laboral. Situación actual y perspectivas. Seminario Internacional, OIT/CINTERFOR/CONOCER. Guanajuato 23-25 de mayo, pp.15-26.

Espacio Europeo de Enseñanza Superior. Declaración conjunta de los Ministros europeos de enseñanza. Declaración de Bologna. Italia, 1999.

González, E. Alfaro, M. Cortés, P. Hernández S. (2012), “Competencias requeridas por el contador auditor, en función a los cambios experimentados por la profesión", CAPIC REVIEW Vol. 10 (1): 53-62, 2012.

Kinnear, Thomas y Taylor, James, (2010) Investigación de Mercados, México, McGraw-Hill, 1993.

Lasaga, O. y Barrycoa, J. (2010); "Competencias profesionales y empleabilidad: la inserción laboral de los licenciados en publicidad y RR.PP"; Universitat Abat Oliba Ceu"; Madrid: CEU Ediciones.

Marques, J. (2001). “Nuevas tendencias en la auditoría", Octubre-Diciembre, Contaduría y Administración $\mathrm{N}^{\circ} 203$, 37- 44. 


\section{ABSTRACT}

Among the objectives formulated in the Bologna Declaration (1999), and in this case, been axis on which the new educational paradigm in higher education is based, it is: "Develop academic, competence and professional qualification criteria to answer the labor market demand the and let respond to the current educational, labor and social challenges". The Berlin Conference (2003), emphasizes the employability of graduates. The Bergen Conference (2005), points out that to improve the employability of graduates, it is necessary to strengthen the dialogue between employers and social agents.

Following the constant changes generated in the profession and the need to adapt to them permanently constant evaluation of the skills and knowledge of professionals in the area of the audit is necessary. This research makes an analysis of the evaluation of the demands of market, professional skills for employment and remuneration of the graduates from the Accountancy program in the city of La Serena, in order to provide updated information on employability factors, as useful input to the orientation of the study programs, mobilizing the brainpower and aligning it to what socio-economic actors demand.

The study sets a mixed perspective. The qualitative trait manifests by obtaining information of the graduates of audit considered like strategic actors, in this case graduates by subjective perceptions and visions that those delivered, while the quantity is expressed in terms of the analysis of data obtained by implementing an insertion surveym l'Agència per a la Qualitat from the System of University of Catalonia (AQU).

The investigation allowed to identify the most valued skills according to the market for recent graduates of Accountancy, and provide the confirmation of the importance of personal characteristics, as a factor in employability. It was determined the existence of a relationship between skills, performance category and level of remuneration, same as the determination of the assessing on quality of work.

Keywords: Employability, Job Placement, Professional skills.

\section{INTRODUCCIÓN}

En un entorno global y competitivo, cada vez más demandante de prácticas eficientes, como actual, surge la necesidad de contar con profesionales capaces de responder a requerimientos de control y revisión continua de procesos y actividades que se ejecutan en los diversas tipos empresas y organizaciones, tanto privadas como gubernamentales.

En las últimas décadas la marcada y constante evolución de la auditoría ha provocado que el auditor no se desempeñe como profesional con un enfoque holístico sino más bien se ha marcado la especialización de este tanto en los aspectos personales, como el las competencias profesionales (Marques 2001).

El profesional de la auditoría desde sus orígenes ha sido vinculado casi en exclusividad a desempeñarse en lo relacionado a preparación, análisis, revisión y validación de estados financieros, de hecho en los orígenes de la profesión se limitaba a la mera vigilancia con la finalidad de evitar fraudes y errores. Luego con el crecimiento de las empresas y la separación de la propiedad de la administración, se hizo necesario garantizar (Marques 2001), la información económica financiera de las organizaciones. En Gran Bretaña, debido a las quiebras que se produjeron durante la revolución industrial, se desarrolló la auditoría para generar confianza en los inversores, cuestión que no tardó en extenderse a otros países. Posteriormente las crisis de Wall Strett de 1929 y las sucesivas crisis hasta hoy, han fortalecido a la profesión tanto del punto de vista ético, técnico, legislativo y de investigación.

De acuerdo al enfoque anterior, los cambios que ha experimentado y sigue experimentando el profesional de la auditoría, lo ha llevado a desempeñarse en distintas áreas, lo que genera diferencias socio-laborales, expresadas en empleabilidad, calidad de empleo y remuneraciones.

La evidencia, demuestra que los profesionales de la Auditoría, egresados de Instituciones de educación superior de la comuna de La Serena, experimentan una significativa variabilidad en los aspectos antes señalado, lo cual hace necesario estudia las causales que generan estas 
diferencias. De esta manera surgen las siguientes interrogantes:

- ¿Existen diferencias en la calidad de empleo y las remuneraciones de los egresados de la carrera de auditoría, en función del área de desempeño en la que se desenvuelven?

- ¿Las competencias profesionales del egresado de carreras de auditoría de la ciudad de La Serena, condicionan la calidad de empleo y su remuneración?

\section{Objetivo general}

Analizar la Valoración a las demandas de mercado, de las competencias profesionales para la inserción laboral y remuneración de los titulados de la carrera de auditoría, en la actualidad para la comuna de La Serena.

\section{Objetivos específicos}

- Analizar situación socio-laboral de los egresados de carreras de Auditoría

- Identificar competencias profesionales requeridas para el egresado de las carreras de Auditoría en la actualidad,

- Describir la relación entre competencias profesionales, empleabilidad y remuneración, a través de relación causa efecto.

\section{Hipótesis}

$\mathrm{H}_{\mathrm{A}}$ : La empleabilidad, remuneraciones y calidad de empleo de los egresados de la carrera de $\mathrm{Au}$ ditoría, está determinada por las competencias profesionales que posea el egresado.

\section{Metodología}

La metodología de la investigación ha sido por siempre el sustento empírico de todo estudio. El cómo se llevará a cabo la investigación y el perfil al que esta responde, son aspectos relevantes de considerar. Tomando en consideración lo anterior, es posible señalar que el presente estudio se enmarca dentro de un diseño no experimental, puesto que se estudia el fenómeno bajo sus condiciones naturales y no se realiza manipulación de las variables, ya que al hacerlo se estarían sesgando los datos al momento de analizarlos.

Con respecto al enfoque, el estudio configura una perspectiva mixta (Hernández 2003). Perspectiva en que se fusionan elementos tanto del área cualitativa como cuantitativa. El rasgo cua- litativo se manifiesta en la obtención de información de agentes estratégicos, en este caso los egresados, mediante las percepciones y visiones subjetivas que estos nos entregan, mientras que lo cuantitativo se expresa en función del análisis de los datos obtenidos en el instrumento aplicado.

Con respecto al tipo de investigación, la metodología utilizada fue inicialmente de carácter exploratorio, para continuar con un estudio de tipo descriptivo. En primer lugar se identifica las competencias profesionales requeridas por el mercado, para el egresado de las carreras de $\mathrm{Au}$ ditoría en la actualidad, en base a información bibliográfica y documental. En segundo lugar se analizó la situación socio laboral de los egresados de las carreras de Auditoría, de instituciones de educación superior de la ciudad de La Serena, analizando aspectos tales como: La situación laboral actual, el acceso al primer empleo, la satisfacción con el trabajo actual, la valoración de los factores de contratación, la remuneración obtenida, la adecuación de la formación recibida al empleo ocupado, la formación continuada, la movilidad, el rendimiento académico y status económico, así como, las acciones emprendidas en caso de estar actualmente desempleado. Para ello se aplicó, como base, entre enero y mayo del año 2015 la encuesta de inserción de l'Agència per a la Qualitat del Sistema Universitari de Catalunya (AQU 2008) por tratarse de un instrumento estadísticamente y sociológicamente validado y utilizado en un estudio similar llamado "Competencias profesionales y empleabilidad: la inserción laboral de los licenciados en publicidad y RR.PP. de la Universitat Abat Oliba Ceu", de las autores Lasaga y Barraycoa 2010.

Siguiendo el esquema de Kinnear y Taylor (1993), los pasos para definir la muestra fueron los siguientes:

\section{a. Población:}

i. Alcance: Instituciones de Educación superior de la Ciudad de La Serena, que cuenten con egresados durante los 4 últimos años.

ii. Tiempo: egresados entre 2011 y 2014.

iii. Elementos: Egresados de instituciones de educación superior de la carrera de Auditoría.

iv. Unidades de muestreo: Todos los egresados de instituciones de educación superior de la carrera de Auditoría, alcanzan un total 324 egresados. 
a. Marco muestral: En concordancia con las restricciones establecidas para la población, los sujetos objeto de estudio, pertenecen solamente a la Universidad de La Serena y a Inacap.

b. Tamaño de la muestra: El estudio se aplicó a 158 egresados de las instituciones señaladas.

c. Procedimiento de muestreo: Se utilizó un muestreo no probabilístico por conveniencia, en función de la accesibilidad de los sujetos para los investigadores.

El trabajo de campo se desarrolló considerando como fuente de información primaria, la aplicación de la encuesta, esta se aplicó a los sujetos de la muestra, en formato papel, así como en formato digital a través de un portal en internet. Como fuente secundaria se utilizó bibliografía relacionada con empleabilidad y competencias, así como las declaraciones y escritos emanados en conferencias como la de Bolonia (1999), la Conferencia de Berlín (2003), la Conferencia de Bergen (2005), entre otros. El procesamiento y análisis de resultados se realizó utilizando herramientas como el diagrama causa efecto, así como el uso de software para determinación de tendencia central y dispersión.

\section{Exposición de Resultados:}

Entre Enero y Mayo del año 2015 se aplicó una encuesta a 158 egresados, entre los años 2011 y 2014, de las carreras de auditoría de la Universidad de La Serena y de INACAP, por ser los programas cumplen con la restricción de tener egresados en los 4 últimos años. En esta encuesta de consultó sobre la situación laboral actual, el acceso al primer empleo, la satisfacción con el trabajo actual, la valoración de los factores de contratación, la remuneración obtenida, la adecuación de la formación recibida al empleo ocupado, la formación continuada, la movilidad, el rendimiento académico, el status económico y acciones emprendidas en caso de estar titulado.

Una vez obtenidos los resultados se procedió a su procesamiento y análisis, utilizando herramientas de análisis, como el diagrama causa efecto y software para determinación de tendencias. Obteniendo los siguientes resultados.

\section{Valoración de los factores de Contratación.}

La selección de personal en las empresas es una variable esencial para valorar la incidencia de la formación en competencias en la inserción laboral. Por lo cual se solicitó a los encuestados una ponderación sobre los factores que han determinado su inserción laboral, Los resultados muestran que las competencias personales son las que tienen mayor valoración (Ver Gráfico 1) Destacando variables como "la manera de ser" y "la capacidad de trabajar en grupos", y sólo destaca una variable que no tiene que ver con la competencia personal que es "la formación Global en la Universidad". Se deduce entonces que la clave del éxito de un proceso de selección "radica en las competencias personales y sociales, tanto si se tienen como si se demuestra la capacidad para desarrollarlas". ${ }^{3}$

Por otra parte los conocimientos teóricos e instrumentales, alcanzan una puntuación baja, dada la percepción de los egresados que a medida que adquieren experiencia profesional lo teórico y lo instrumental se adquiere fácilmente. Además en esta carrera en particular el avance de las normas y la teoría es muy rápido, por lo cual una parte de la formación de hoy puede quedar obsoleta mañana. Por ello más que conocimientos teóricos, las empresas aprecian, como una cualidad personal importante, la capacidad de aprendizaje y adaptación.

3 BARRAYCOA MARTÍNEZ, J. y LASAGA MILLET, O., Competencias e inserción laboral: un análisis de la empleabilidad en los recién licenciados en Ade y Economía. Madrid: CEU Ediciones, 2009, pág. 134. 


\section{Gráfico 1: "VALORACIÓN DE LOS FACTORES DE CONTRATACIÓN"}

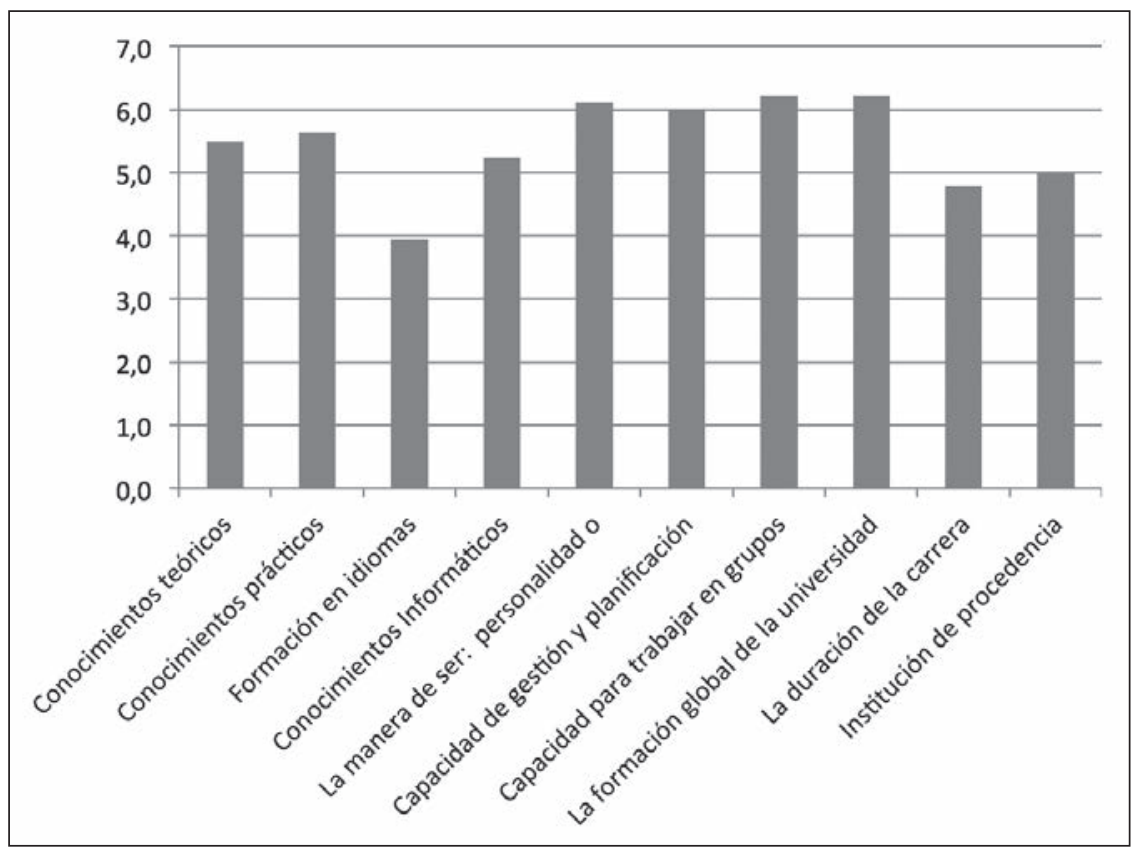

Fuente: Elaboración Propia año 2015.

2. Competencias Transversales: Comparativo entre los conocimientos adquiridos en la universidad $v / s$ su utilidad en el trabajo.

En la encuesta aplicada, se solicitó a los egresados que puntúen de 1 (muy bajo) a 7 (muy bueno) el nivel que adquirieron en la Universidad y su adecuación para el desempeño de su trabajo respecto a diversos aspectos relacionados tanto con la formación como con las competencias:

- Conocimientos teóricos

- Formación práctica

- Competencias instrumentales: informática e idiomas.

- Competencias sociales: trabajo en equipo y comunicación tanto oral como escrita.

- Competencias personales: liderazgo, gestión, resolución de problemas, toma de decisiones, creatividad y pensamiento crítico.
$\mathrm{Al}$ analizar la relación entre la formación en conocimientos y competencias adquirida a lo largo de los estudios de Contador Auditor. y su utilidad en el empleo, destaca que se mantienen las tendencias de opinión (véase gráfico 2). De todas formas se observa lo siguiente:

- La Valoración de las competencias es pareja, es decir no hay grandes diferencias de puntuación

- Las Competencias Instrumentales (Informática e idiomas), son las menos valoradas.

- Se han adquirido en el grado adecuado para el empleo: entre ellas están la expresión oral y escrita, el liderazgo, la resolución de problemas, la creatividad, el pensamiento crítico y los idiomas.

- La competencia social más valorada es el "trabajo en equipo".

- Y en las competencias personales destaca la "resolución de problemas"

- Además se valora más la competencia en la aplicación en el trabajo. 
Gráfico 2: “COMPARATIVA ENTRE EL NIVEL DE COMPETENCIAS ADQUIRIDO EN LA UNIVERSIDAD Y EL REQUERIDO PARA EL DESEMPEÑO DEL PUESTO DE TRABAJO”

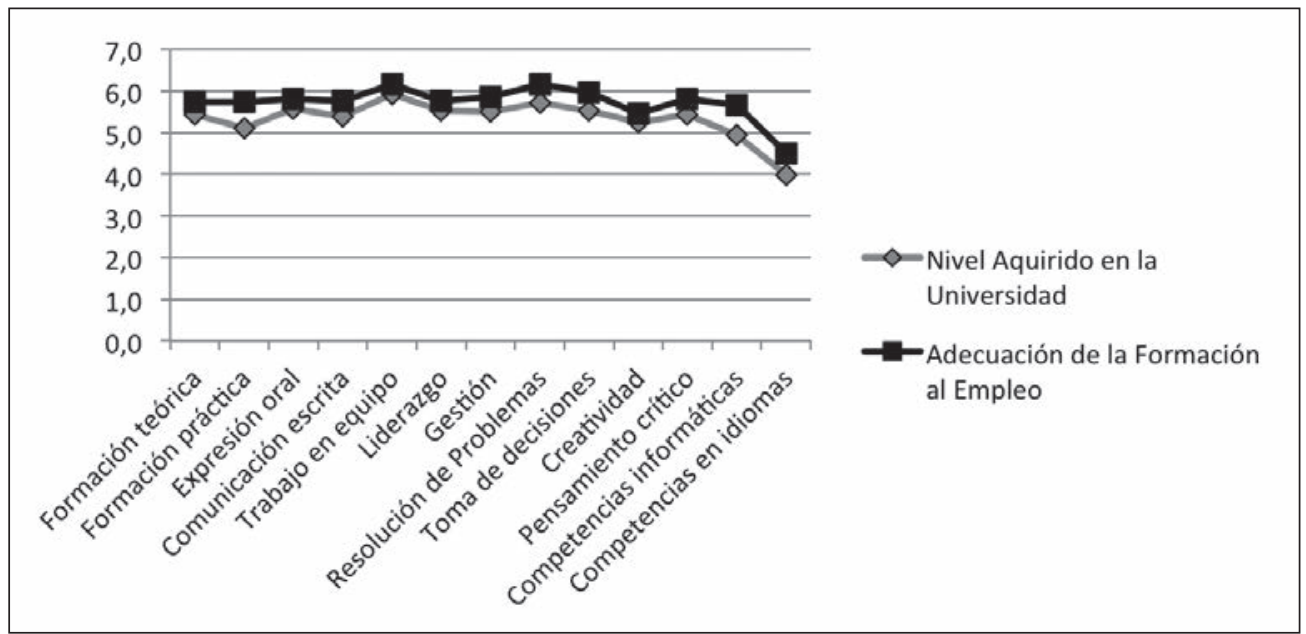

Fuente: Elaboración Propia año 2015.

\section{Sueldos.}

El sueldo bruto promedio en los egresados de la carrera de Auditoría entre los años 2011 y 2014 de la ciudad de La Serena es de \$714.768, registrándose el mayor sueldo por un monto bruto de $\$ 1.970 .000$ de un egresado que trabaja en el área de Recursos Humanos en el rubro de la minería, y el menor sueldo de $\$ 310.000$ corres- ponde a un egresado que trabaja como analista contable en una empresa de asesorías contables.

Se realizó un comparativo entre los sueldos brutos promedio según año de egreso y los datos entregados por el sitio Mi futuro.cl ${ }^{4}$, en el cual se puede ver que los egresados de la Ciudad de la Serena están por debajo de los promedios Nacionales

Tabla I: "COMPARATIVO ENTRE SUELDOS NACIONALES V/S CIUDAD DE LA SERENA"

\begin{tabular}{|l|c|c|}
\hline Años de Egreso & $\begin{array}{c}\text { Sueldo Promedio } \\
\text { según encuesta }\end{array}$ & $\begin{array}{c}\text { Sueldo } \\
\text { Promedio, según } \\
\text { mifuturo.cl }\end{array}$ \\
\hline Egresados 2011 & 984.152 & 1.132 .154 \\
\hline Egresados 2012 & 710.892 & 1.041 .866 \\
\hline Egresados 2013 & 634.926 & 941.312 \\
\hline Egresados 2014 & 596.152 & 855.901 \\
\hline
\end{tabular}

Fuente: Elaboración Propia, año 2015.

También se efectuó un análisis respecto de los sueldos según la actividad económica en la que desenvuelven los egresados (Ver tabla $\mathrm{N}^{\circ} 2$ ), en donde se observó que las actividades que en- tregan mejor remuneración son las "asesorías" y el sector de "la minería" y la remuneración más baja está en los "servicios contables". 
Tabla II: "REMUNERACIÓN SEGÚN ACTIVIDAD ECONÓMICA"

\begin{tabular}{|l|c|r|}
\hline \multicolumn{1}{|c|}{ Actividad Económica } & Sueldos Promedio & \multicolumn{1}{c|}{$\%$} \\
\hline Auditoría & 796.587 & $21 \%$ \\
\hline Servicios Contables & 493.467 & $14 \%$ \\
\hline Minería & 841.862 & $13 \%$ \\
\hline Inmobiliario & 622.113 & $5 \%$ \\
\hline Salud & 476.872 & $5 \%$ \\
\hline Servicio Público & 760.711 & $5 \%$ \\
\hline Asesorías & 1.031 .200 & $5 \%$ \\
\hline Portuaria & 672.500 & $4 \%$ \\
\hline Educación & 650.585 & $4 \%$ \\
\hline Otros & 688.844 & $27 \%$ \\
\hline
\end{tabular}

Fuente: Elaboración Propia año 2015.

En el análisis de las remuneraciones, se analizó también el nivel de sueldo de acuerdo al área de desempeño (Ver Tabla $N^{\circ} 3$ ), destacando las mayores remuneraciones en las áreas de "recursos humanos" y "Finanzas" y la con menor remuneración "Contabilidad".

Tabla III: “REMUNERACIÓN SEGÚN ÁREA DE DESEMPEÑO”

\begin{tabular}{|l|c|r|}
\hline \multicolumn{1}{|c|}{ Aréa de Desempeño } & Sueldos Promedio & \multicolumn{1}{c|}{$\%$} \\
\hline Administración & 731.400 & $9 \%$ \\
\hline Auditoría & 729.368 & $17 \%$ \\
\hline Contabilidad & 632.424 & $39 \%$ \\
\hline Control Interno & 690.926 & $5 \%$ \\
\hline Finanzas & 798.733 & $6 \%$ \\
\hline Recursos Humanos & 960.857 & $3 \%$ \\
\hline Tesorería & 428.121 & $10 \%$ \\
\hline Tributaria & 846.864 & \\
\hline
\end{tabular}

Fuente: Elaboración Propia, año 2015.

4. Valoración del Trabajo: Comparativo entre mejor remuneración y mejor trabajo

En la encuesta aplicada, se solicitó a los egresados que puntúen de 1 (muy bajo) a 7 (muy bueno) en cuanto a la opción de optar a una mejor remuneración $\mathrm{v} / \mathrm{s}$ obtener un mejor trabajo de acuerdo al área de especialización entre las que se consideraron las siguientes: Auditoría, Contabilidad Avanzada, Tributación, Recursos Humanos, Tecnologías de la Información, Finanzas, Costos, Administración y Gestión.
$\mathrm{Al}$ analizar la relación entre mejor remuneración y mejor trabaja al que opta el egresado de Contador Auditor., se puede observar que existe similares tendencias (véase gráfico 3 ). De todas formas se observa lo siguiente:

- Las áreas con mayor valoración son "Tributaria", "Contabilidad Avanzada" y "Auditoría"

- Las de menor valoración son "Recursos Humanos", "Tecnologías de Información" y "Costos". 


\section{Gráfico 3: “COMPARATIVA ENTRE OPCIÓN A MEJOR REMUNERACIÓN V/S MEJOR TRABAJO"}

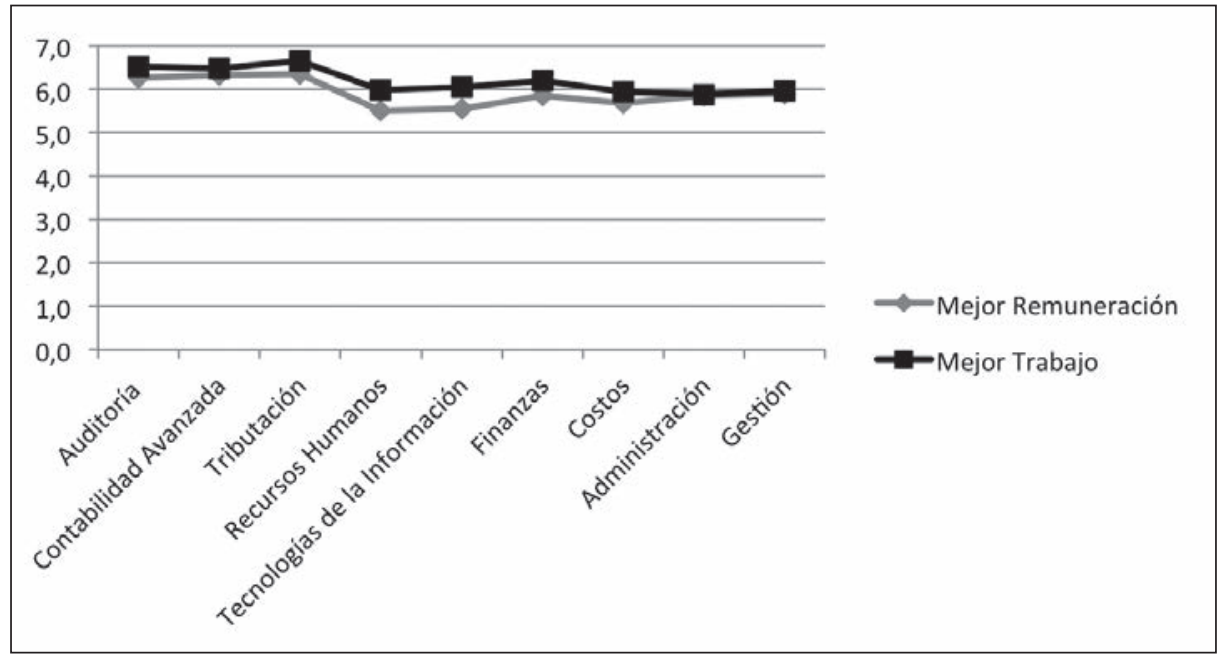

Fuente: Elaboración Propia, año 2015.

\section{Progresión Económica}

Se realizó una análisis respecto de la progresión socio económica de los alumnos identificando 2 variables: Primero el nivel socio económico en el que se clasifican y Segundo la progresión económica después de sus estudios. Respecto de la primera variable (Ver Tabla $\mathrm{N}^{\circ} 4$ ), se observa que el $90 \%$ de los egresados se clasifica en los estratos $\mathrm{C} 2$ y $\mathrm{C} 3$.

Tabla IV: “NIVEL SOCIO ECONÓMICO”

\begin{tabular}{|c|c|}
\hline Nivel Socio Económico & $\%$ \\
\hline ABC1 & $2 \%$ \\
\hline C2 & $45 \%$ \\
\hline C3 & $45 \%$ \\
\hline D & $7 \%$ \\
\hline E & $0 \%$ \\
\hline
\end{tabular}

Fuente: Elaboración Propia año 2015.

Respecto de la segunda variable, se observó que el $44 \%$ de los egresados mantenía el mismo Nivel Socio Económico, 47\% aumentaba un nivel y el 8\% aumentaba dos niveles, dándose sólo un $1 \%$ de retroceso de nivel socio económico.

\section{Desempleo}

Respecto de los egresados desempleados, estos representaron el $12 \%$ de la muestra. Las principales razones del desempleo fueron "Maternidad y Familia", "Continuidad de estudios", es decir más bien razones de población inactiva. A este grupo se les solicitó que valorarán con puntuación de 1 (nada de importante) a 7 (muy importante), las dificultades para encontrar empleo, lo cual arrojó los siguientes resultados (Ver Tabla N`5): 
Tabla V: “DIFICULTAD PARA ENCONTRAR EMPLEO”

\begin{tabular}{|l|c|}
\hline Dificultad & Nota \\
\hline Carencia en la formación universitaria recibida & 3,1 \\
\hline Actividades personales que te impiden trabajar & 3,9 \\
\hline Falta de práctica profesional & 2,9 \\
\hline Exigencia de tener un trabajo que me guste & 4,6 \\
\hline Falta de conocimiento del mercado laboral & 4,4 \\
\hline Exigencia de tener un trabajo bien remunerado & 4,6 \\
\hline Falta de conocimiento de idiomas & 3,1 \\
\hline Falta de conocimiento de Informática & 3,4 \\
\hline La formación global de la universidad & 3,8 \\
\hline
\end{tabular}

Fuente: Elaboración Propia, año 2015.

Como se puede observar las con mayor puntuación son las exigencias de tener un trabajo que me guste y bien remunerado, es decir un convencimiento personal más que razones de mercado.

\section{CONCLUSIÓN}

En esta investigación se pudo identificar cuáles son las competencias más valoradas en el mercado para los Contadores Auditores recientemente egresados, además se pudo analizar su nivel de remuneraciones y su valoración de la calidad del trabajo. Los resultados, evidencian que los egresados participan de la cultura de las competencias y son capaces de discriminar con un elevado grado de precisión el nivel de adquisición y dominio de las competencias sobre las que se les inquiere. Asimismo, tienen una capacidad crítica acerca de los desajustes entre su formación y las necesidades profesionales.

Cuando se aborda el estudio de las competencias desde la perspectiva de los empleadores o mediante el análisis de las ofertas de trabajo, se enriquece considerablemente la comprensión de las competencias. Realizar el esfuerzo de analizar las competencias de forma integral es indispensable, dada su importancia y correlación con la inserción laboral, como se ha detectado en el estudio piloto.

Los resultados obtenidos, permiten visualizar una valoración destacada, dentro de los factores de contratación a la formación global de la Universidad, así como, a la capacidad de trabajar en grupo.

En cuanto a la remuneración se evidenció para cada una de las cohortes estudiadas, valores descendidos respecto de la media nacional. Esta situación puede verse influida por el nivel socioeconómico inicial de los egresados y el ascenso evidenciado. Presentan niveles de ingresos, significativamente superiores, los obtenidos, en primer lugar, quienes se desempeñan realizando asesoría y en segundo lugar, aquellos que trabajan en empresas del rubro minero. Así mismo, se pudo observar, mayores ingresos obtenidos por quienes se desempeñan en el área de recursos humanos, seguido por tributaria y finanzas, siendo del área contable, quienes reciben las remuneraciones más bajas.

En lo referente a la percepción de calidad del trabajo, considerando aspectos, como horarios, ambiente laboral, capacidad de promoción, entre otros, se destaca, quienes trabajan en el área de la tributación y empresas auditoras.

La información presentada de los factores de empleabilidad, pueden transformarse un insumo útil, para la orientación de nuevos planes y programas de estudios, que estén acorde con las necesidades de mercado en función de la valoración otorgada, en coherencia con el paradigma actual de la educación superior.

En consideración a una de las funciones y obligaciones de las instituciones de educación superior, que es el la de preparar estudiantes para un mercado de trabajo específico, que requiere educación formal avanzada, con competencias y cualificación profesional para responder a las demandas presentadas y así conseguir mayor y mejor empleabilidad. Por consiguiente resulta necesario e indispensable, conocer dichas demandas, así como adaptarse a los nuevos requerimientos establecidos por los cambios 
frecuentes en los escenarios. Para los programas asociados a la auditoría, en la Comuna de la Serena, estos en la actualidad y de acuerdo a la percepción de profesionales egresados de éstas carreras, se debería fortalecer las áreas de Recursos Humanos, Finanzas, así como las competencias para el desarrollo de asistencia técnica y desempeño en sectores económicos específicos como minería y sector público, adicionales a las tradicionalmente fortalecidas, como contabilidad, tributaria y administración.

\section{BIBLIOGRAFIA}

Ayats, J.C. Zamora, P. Desantes, R., (2015) La Empleabilidad de los Titulados como Pilar Básico del Espacio Europeo de la Educación Superior, XIII CUIEET, Maspalomas (Gran Canaria).

Barraycoa Martínez, J. y Lasaga Millet, O., (2010), Competencias e inserción laboral: un análisis de la empleabilidad en los recién licenciados en Ade y Economía. Madrid: CEU Ediciones.

Ducci, María Angélica (1996). “El enfoque de competencia laboral en la perspectiva internacional", en Formación basada en competencia laboral. Situación actual y perspectivas. Seminario Internacional, OIT/CINTERFOR/CONOCER. Guanajuato 23-25 de mayo, pp.15-26.

Espacio Europeo de Enseñanza Superior. Declaración conjunta de los Ministros europeos de enseñanza. Declaración de Bologna. Italia, 1999.

González, E. Alfaro, M. Cortés, P. Hernández S. (2012), “Competencias requeridas por el contador auditor, en función a los cambios experimentados por la profesión", CAPIC REVIEW Vol. 10 (1): 53-62, 2012.

Kinnear, Thomas y Taylor, James, (2010) Investigación de Mercados, México, McGraw-Hill, 1993.

Lasaga, O. y Barrycoa, J. (2010); "Competencias profesionales y empleabilidad: la inserción laboral de los licenciados en publicidad y RR.PP"; Universitat Abat Oliba Ceu"; Madrid: CEU Ediciones.

Marques, J. (2001). “Nuevas tendencias en la auditoría", Octubre-Diciembre, Contaduría y Administración $\mathrm{N}^{\circ} 203$, 37- 44. 


\title{
COMPETENCIAS PROFESIONALES Y LA EMPLEABILIDAD, PARA EGRESADOS $Y$ TITULADOS DE LA CARRERA DE AUDITORÍA.
}

\author{
PROFESSIONAL SKILLS RELATED TO \\ EMPLOYABILITY FOR GRADUATES CAREER \\ AUDIT.
}

\author{
Emilio Enrique González Díaz ${ }^{1}$ y Mauricio Iván Alfaro Castillo
}

\section{RESUMEN}

Entre los objetivos formulados en la declaración de Bolonia (1999), y que son el eje sobre el que se sustenta el nuevo paradigma educativo en la educación superior, se encuentra: "Formular criterios académicos, competenciales y de cualificación profesional que respondan a la demanda del mercado laboral y que permitan responder a los retos educativo, laborales y sociales actuales". La Conferencia de Berlín (2003), pone énfasis en la empleabilidad de los graduados, La Conferencia de Bergen (2005), señala que para mejorar el empleo de los graduados, es necesario reforzar el diálogo con Empleadores y Agentes sociales.

A raíz de los constantes cambios generados en la profesión y la necesidad de adecuarse a ellos permanentemente, se hace necesaria una evaluación constante de las capacidades y conocimientos de los profesionales del área de la auditoría. La presente investigación realiza un análisis de la valoración de las demandas de mercado, de las competencias profesionales para la inserción laboral y remuneración de los titulados de la carrera de Auditoría en la Ciudad de La Serena, con el objetivo de entregar información actualizada de los factores de empleabilidad, como insumo útil, para la orientación de los planes y programas de estudios, movilizando el capital intelectual y alineándolo a lo demandado por los agentes socioeconómicos.

El estudio se configuró una perspectiva mixta., El rasgo cualitativo se manifiesta en la obtención de información de los egresados de carreras de auditoría, considerados como agentes estratégicos mediante las percepciones y visiones subjetivas que estos entregan, mientras que lo cuantitativo se expresa en función del análisis de datos obtenidos en la aplicación de la encuesta de inserción de l'Agència per a la Qualitat del Sistema Universitari de Catalunya (AQU).

La investigación permitió identificar las competencias profesionales más valoradas en el mercado para los Contadores Auditores recientemente egresados, así como, confirmar la importancia de las características personales, como factor determinante en la empleabilidad. Se determinó que los egresados establecían una relación entre competencias, rubro de desempeño y el nivel de remuneraciones, así como una valoración de la calidad del trabajo.

Palabras claves: Competencias Profesionales, Empleabilidad, Inserción Laboral.

Recepción: 17/06/2016. Aprobación: 26/09//2016.

1 Departamento de Ciencias Económicas y Empresariales, Facultad de Ciencias Sociales y Económicas, Universidad de La Serena, La Serena, Chile, eegonzalez@userena.cl

2 Departamento de Ciencias Económicas y Empresariales, Facultad de Ciencias Sociales y Económicas, Universidad de La Serena, La Serena, Chile, malfaroc@userena.cl 


\section{ABSTRACT}

Among the objectives formulated in the Bologna Declaration (1999), and in this case, been axis on which the new educational paradigm in higher education is based, it is: "Develop academic, competence and professional qualification criteria to answer the labor market demand the and let respond to the current educational, labor and social challenges". The Berlin Conference (2003), emphasizes the employability of graduates. The Bergen Conference (2005), points out that to improve the employability of graduates, it is necessary to strengthen the dialogue between employers and social agents.

Following the constant changes generated in the profession and the need to adapt to them permanently constant evaluation of the skills and knowledge of professionals in the area of the audit is necessary. This research makes an analysis of the evaluation of the demands of market, professional skills for employment and remuneration of the graduates from the Accountancy program in the city of La Serena, in order to provide updated information on employability factors, as useful input to the orientation of the study programs, mobilizing the brainpower and aligning it to what socio-economic actors demand.

The study sets a mixed perspective. The qualitative trait manifests by obtaining information of the graduates of audit considered like strategic actors, in this case graduates by subjective perceptions and visions that those delivered, while the quantity is expressed in terms of the analysis of data obtained by implementing an insertion surveym l'Agència per a la Qualitat from the System of University of Catalonia (AQU).

The investigation allowed to identify the most valued skills according to the market for recent graduates of Accountancy, and provide the confirmation of the importance of personal characteristics, as a factor in employability. It was determined the existence of a relationship between skills, performance category and level of remuneration, same as the determination of the assessing on quality of work.

Keywords: Employability, Job Placement, Professional skills.

\section{INTRODUCCIÓN}

En un entorno global y competitivo, cada vez más demandante de prácticas eficientes, como actual, surge la necesidad de contar con profesionales capaces de responder a requerimientos de control y revisión continua de procesos y actividades que se ejecutan en los diversas tipos empresas y organizaciones, tanto privadas como gubernamentales.

En las últimas décadas la marcada y constante evolución de la auditoría ha provocado que el auditor no se desempeñe como profesional con un enfoque holístico sino más bien se ha marcado la especialización de este tanto en los aspectos personales, como el las competencias profesionales (Marques 2001).

El profesional de la auditoría desde sus orígenes ha sido vinculado casi en exclusividad a desempeñarse en lo relacionado a preparación, análisis, revisión y validación de estados financieros, de hecho en los orígenes de la profesión se limitaba a la mera vigilancia con la finalidad de evitar fraudes y errores. Luego con el crecimiento de las empresas y la separación de la propiedad de la administración, se hizo necesario garantizar (Marques 2001), la información económica financiera de las organizaciones. En Gran Bretaña, debido a las quiebras que se produjeron durante la revolución industrial, se desarrolló la auditoría para generar confianza en los inversores, cuestión que no tardó en extenderse a otros países. Posteriormente las crisis de Wall Strett de 1929 y las sucesivas crisis hasta hoy, han fortalecido a la profesión tanto del punto de vista ético, técnico, legislativo y de investigación.

De acuerdo al enfoque anterior, los cambios que ha experimentado y sigue experimentando el profesional de la auditoría, lo ha llevado a desempeñarse en distintas áreas, lo que genera diferencias socio-laborales, expresadas en empleabilidad, calidad de empleo y remuneraciones.

La evidencia, demuestra que los profesionales de la Auditoría, egresados de Instituciones de educación superior de la comuna de La Serena, experimentan una significativa variabilidad en los aspectos antes señalado, lo cual hace necesario estudia las causales que generan estas 
diferencias. De esta manera surgen las siguientes interrogantes:

- ¿Existen diferencias en la calidad de empleo y las remuneraciones de los egresados de la carrera de auditoría, en función del área de desempeño en la que se desenvuelven?

- ¿Las competencias profesionales del egresado de carreras de auditoría de la ciudad de La Serena, condicionan la calidad de empleo y su remuneración?

\section{Objetivo general}

Analizar la Valoración a las demandas de mercado, de las competencias profesionales para la inserción laboral y remuneración de los titulados de la carrera de auditoría, en la actualidad para la comuna de La Serena.

\section{Objetivos específicos}

- Analizar situación socio-laboral de los egresados de carreras de Auditoría

- Identificar competencias profesionales requeridas para el egresado de las carreras de Auditoría en la actualidad,

- Describir la relación entre competencias profesionales, empleabilidad y remuneración, a través de relación causa efecto.

\section{Hipótesis}

$\mathrm{H}_{\mathrm{A}}$ : La empleabilidad, remuneraciones y calidad de empleo de los egresados de la carrera de $\mathrm{Au}$ ditoría, está determinada por las competencias profesionales que posea el egresado.

\section{Metodología}

La metodología de la investigación ha sido por siempre el sustento empírico de todo estudio. El cómo se llevará a cabo la investigación y el perfil al que esta responde, son aspectos relevantes de considerar. Tomando en consideración lo anterior, es posible señalar que el presente estudio se enmarca dentro de un diseño no experimental, puesto que se estudia el fenómeno bajo sus condiciones naturales y no se realiza manipulación de las variables, ya que al hacerlo se estarían sesgando los datos al momento de analizarlos.

Con respecto al enfoque, el estudio configura una perspectiva mixta (Hernández 2003). Perspectiva en que se fusionan elementos tanto del área cualitativa como cuantitativa. El rasgo cua- litativo se manifiesta en la obtención de información de agentes estratégicos, en este caso los egresados, mediante las percepciones y visiones subjetivas que estos nos entregan, mientras que lo cuantitativo se expresa en función del análisis de los datos obtenidos en el instrumento aplicado.

Con respecto al tipo de investigación, la metodología utilizada fue inicialmente de carácter exploratorio, para continuar con un estudio de tipo descriptivo. En primer lugar se identifica las competencias profesionales requeridas por el mercado, para el egresado de las carreras de $\mathrm{Au}$ ditoría en la actualidad, en base a información bibliográfica y documental. En segundo lugar se analizó la situación socio laboral de los egresados de las carreras de Auditoría, de instituciones de educación superior de la ciudad de La Serena, analizando aspectos tales como: La situación laboral actual, el acceso al primer empleo, la satisfacción con el trabajo actual, la valoración de los factores de contratación, la remuneración obtenida, la adecuación de la formación recibida al empleo ocupado, la formación continuada, la movilidad, el rendimiento académico y status económico, así como, las acciones emprendidas en caso de estar actualmente desempleado. Para ello se aplicó, como base, entre enero y mayo del año 2015 la encuesta de inserción de l'Agència per a la Qualitat del Sistema Universitari de Catalunya (AQU 2008) por tratarse de un instrumento estadísticamente y sociológicamente validado y utilizado en un estudio similar llamado "Competencias profesionales y empleabilidad: la inserción laboral de los licenciados en publicidad y RR.PP. de la Universitat Abat Oliba Ceu", de las autores Lasaga y Barraycoa 2010.

Siguiendo el esquema de Kinnear y Taylor (1993), los pasos para definir la muestra fueron los siguientes:

\section{a. Población:}

i. Alcance: Instituciones de Educación superior de la Ciudad de La Serena, que cuenten con egresados durante los 4 últimos años.

ii. Tiempo: egresados entre 2011 y 2014.

iii. Elementos: Egresados de instituciones de educación superior de la carrera de Auditoría.

iv. Unidades de muestreo: Todos los egresados de instituciones de educación superior de la carrera de Auditoría, alcanzan un total 324 egresados. 
a. Marco muestral: En concordancia con las restricciones establecidas para la población, los sujetos objeto de estudio, pertenecen solamente a la Universidad de La Serena y a Inacap.

b. Tamaño de la muestra: El estudio se aplicó a 158 egresados de las instituciones señaladas.

c. Procedimiento de muestreo: Se utilizó un muestreo no probabilístico por conveniencia, en función de la accesibilidad de los sujetos para los investigadores.

El trabajo de campo se desarrolló considerando como fuente de información primaria, la aplicación de la encuesta, esta se aplicó a los sujetos de la muestra, en formato papel, así como en formato digital a través de un portal en internet. Como fuente secundaria se utilizó bibliografía relacionada con empleabilidad y competencias, así como las declaraciones y escritos emanados en conferencias como la de Bolonia (1999), la Conferencia de Berlín (2003), la Conferencia de Bergen (2005), entre otros. El procesamiento y análisis de resultados se realizó utilizando herramientas como el diagrama causa efecto, así como el uso de software para determinación de tendencia central y dispersión.

\section{Exposición de Resultados:}

Entre Enero y Mayo del año 2015 se aplicó una encuesta a 158 egresados, entre los años 2011 y 2014, de las carreras de auditoría de la Universidad de La Serena y de INACAP, por ser los programas cumplen con la restricción de tener egresados en los 4 últimos años. En esta encuesta de consultó sobre la situación laboral actual, el acceso al primer empleo, la satisfacción con el trabajo actual, la valoración de los factores de contratación, la remuneración obtenida, la adecuación de la formación recibida al empleo ocupado, la formación continuada, la movilidad, el rendimiento académico, el status económico y acciones emprendidas en caso de estar titulado.

Una vez obtenidos los resultados se procedió a su procesamiento y análisis, utilizando herramientas de análisis, como el diagrama causa efecto y software para determinación de tendencias. Obteniendo los siguientes resultados.

\section{Valoración de los factores de Contratación.}

La selección de personal en las empresas es una variable esencial para valorar la incidencia de la formación en competencias en la inserción laboral. Por lo cual se solicitó a los encuestados una ponderación sobre los factores que han determinado su inserción laboral, Los resultados muestran que las competencias personales son las que tienen mayor valoración (Ver Gráfico 1) Destacando variables como "la manera de ser" y "la capacidad de trabajar en grupos", y sólo destaca una variable que no tiene que ver con la competencia personal que es "la formación Global en la Universidad". Se deduce entonces que la clave del éxito de un proceso de selección "radica en las competencias personales y sociales, tanto si se tienen como si se demuestra la capacidad para desarrollarlas". ${ }^{3}$

Por otra parte los conocimientos teóricos e instrumentales, alcanzan una puntuación baja, dada la percepción de los egresados que a medida que adquieren experiencia profesional lo teórico y lo instrumental se adquiere fácilmente. Además en esta carrera en particular el avance de las normas y la teoría es muy rápido, por lo cual una parte de la formación de hoy puede quedar obsoleta mañana. Por ello más que conocimientos teóricos, las empresas aprecian, como una cualidad personal importante, la capacidad de aprendizaje y adaptación.

3 BARRAYCOA MARTÍNEZ, J. y LASAGA MILLET, O., Competencias e inserción laboral: un análisis de la empleabilidad en los recién licenciados en Ade y Economía. Madrid: CEU Ediciones, 2009, pág. 134. 


\section{Gráfico 1: "VALORACIÓN DE LOS FACTORES DE CONTRATACIÓN"}

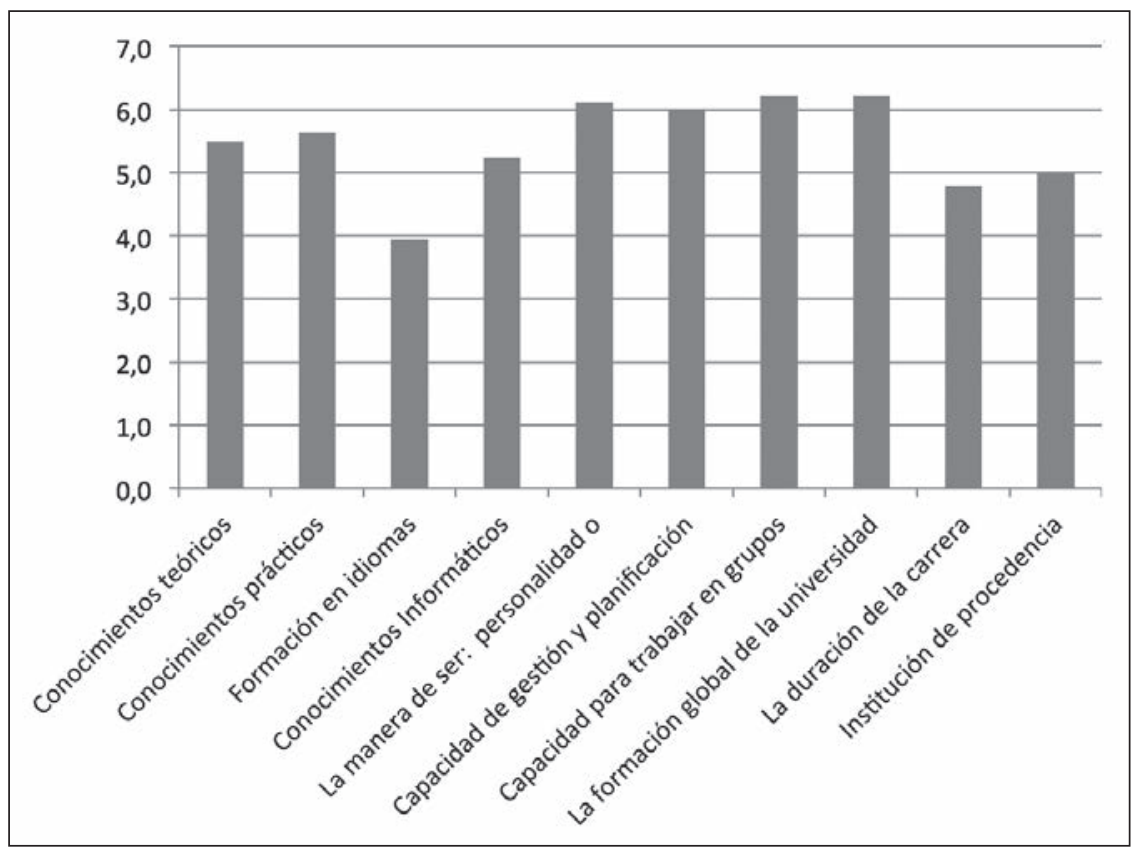

Fuente: Elaboración Propia año 2015.

2. Competencias Transversales: Comparativo entre los conocimientos adquiridos en la universidad $v / s$ su utilidad en el trabajo.

En la encuesta aplicada, se solicitó a los egresados que puntúen de 1 (muy bajo) a 7 (muy bueno) el nivel que adquirieron en la Universidad y su adecuación para el desempeño de su trabajo respecto a diversos aspectos relacionados tanto con la formación como con las competencias:

- Conocimientos teóricos

- Formación práctica

- Competencias instrumentales: informática e idiomas.

- Competencias sociales: trabajo en equipo y comunicación tanto oral como escrita.

- Competencias personales: liderazgo, gestión, resolución de problemas, toma de decisiones, creatividad y pensamiento crítico.
$\mathrm{Al}$ analizar la relación entre la formación en conocimientos y competencias adquirida a lo largo de los estudios de Contador Auditor. y su utilidad en el empleo, destaca que se mantienen las tendencias de opinión (véase gráfico 2). De todas formas se observa lo siguiente:

- La Valoración de las competencias es pareja, es decir no hay grandes diferencias de puntuación

- Las Competencias Instrumentales (Informática e idiomas), son las menos valoradas.

- Se han adquirido en el grado adecuado para el empleo: entre ellas están la expresión oral y escrita, el liderazgo, la resolución de problemas, la creatividad, el pensamiento crítico y los idiomas.

- La competencia social más valorada es el "trabajo en equipo".

- Y en las competencias personales destaca la "resolución de problemas"

- Además se valora más la competencia en la aplicación en el trabajo. 
Gráfico 2: “COMPARATIVA ENTRE EL NIVEL DE COMPETENCIAS ADQUIRIDO EN LA UNIVERSIDAD Y EL REQUERIDO PARA EL DESEMPEÑO DEL PUESTO DE TRABAJO”

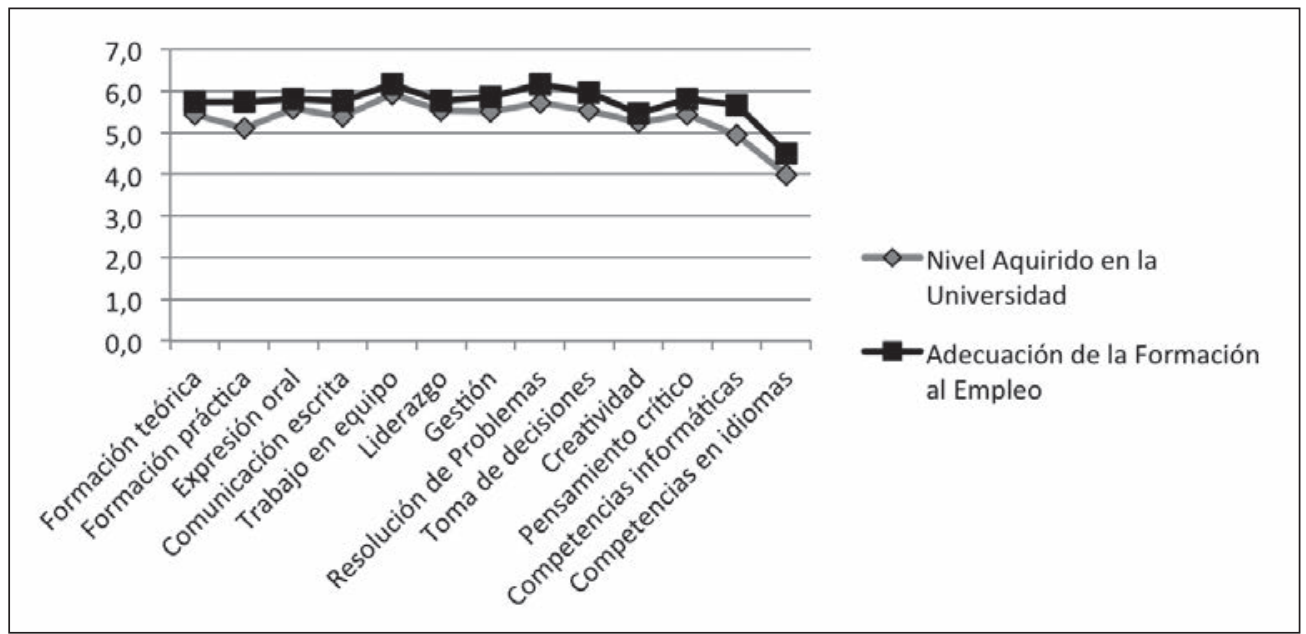

Fuente: Elaboración Propia año 2015.

\section{Sueldos.}

El sueldo bruto promedio en los egresados de la carrera de Auditoría entre los años 2011 y 2014 de la ciudad de La Serena es de \$714.768, registrándose el mayor sueldo por un monto bruto de $\$ 1.970 .000$ de un egresado que trabaja en el área de Recursos Humanos en el rubro de la minería, y el menor sueldo de $\$ 310.000$ corres- ponde a un egresado que trabaja como analista contable en una empresa de asesorías contables.

Se realizó un comparativo entre los sueldos brutos promedio según año de egreso y los datos entregados por el sitio Mi futuro.cl ${ }^{4}$, en el cual se puede ver que los egresados de la Ciudad de la Serena están por debajo de los promedios Nacionales

Tabla I: "COMPARATIVO ENTRE SUELDOS NACIONALES V/S CIUDAD DE LA SERENA"

\begin{tabular}{|l|c|c|}
\hline Años de Egreso & $\begin{array}{c}\text { Sueldo Promedio } \\
\text { según encuesta }\end{array}$ & $\begin{array}{c}\text { Sueldo } \\
\text { Promedio, según } \\
\text { mifuturo.cl }\end{array}$ \\
\hline Egresados 2011 & 984.152 & 1.132 .154 \\
\hline Egresados 2012 & 710.892 & 1.041 .866 \\
\hline Egresados 2013 & 634.926 & 941.312 \\
\hline Egresados 2014 & 596.152 & 855.901 \\
\hline
\end{tabular}

Fuente: Elaboración Propia, año 2015.

También se efectuó un análisis respecto de los sueldos según la actividad económica en la que desenvuelven los egresados (Ver tabla $\mathrm{N}^{\circ} 2$ ), en donde se observó que las actividades que en- tregan mejor remuneración son las "asesorías" y el sector de "la minería" y la remuneración más baja está en los "servicios contables". 
Tabla II: "REMUNERACIÓN SEGÚN ACTIVIDAD ECONÓMICA"

\begin{tabular}{|l|c|r|}
\hline \multicolumn{1}{|c|}{ Actividad Económica } & Sueldos Promedio & \multicolumn{1}{c|}{$\%$} \\
\hline Auditoría & 796.587 & $21 \%$ \\
\hline Servicios Contables & 493.467 & $14 \%$ \\
\hline Minería & 841.862 & $13 \%$ \\
\hline Inmobiliario & 622.113 & $5 \%$ \\
\hline Salud & 476.872 & $5 \%$ \\
\hline Servicio Público & 760.711 & $5 \%$ \\
\hline Asesorías & 1.031 .200 & $5 \%$ \\
\hline Portuaria & 672.500 & $4 \%$ \\
\hline Educación & 650.585 & $4 \%$ \\
\hline Otros & 688.844 & $27 \%$ \\
\hline
\end{tabular}

Fuente: Elaboración Propia año 2015.

En el análisis de las remuneraciones, se analizó también el nivel de sueldo de acuerdo al área de desempeño (Ver Tabla $N^{\circ} 3$ ), destacando las mayores remuneraciones en las áreas de "recursos humanos" y "Finanzas" y la con menor remuneración "Contabilidad".

Tabla III: “REMUNERACIÓN SEGÚN ÁREA DE DESEMPEÑO”

\begin{tabular}{|l|c|r|}
\hline \multicolumn{1}{|c|}{ Aréa de Desempeño } & Sueldos Promedio & \multicolumn{1}{c|}{$\%$} \\
\hline Administración & 731.400 & $9 \%$ \\
\hline Auditoría & 729.368 & $17 \%$ \\
\hline Contabilidad & 632.424 & $39 \%$ \\
\hline Control Interno & 690.926 & $5 \%$ \\
\hline Finanzas & 798.733 & $6 \%$ \\
\hline Recursos Humanos & 960.857 & $3 \%$ \\
\hline Tesorería & 428.121 & $10 \%$ \\
\hline Tributaria & 846.864 & \\
\hline
\end{tabular}

Fuente: Elaboración Propia, año 2015.

4. Valoración del Trabajo: Comparativo entre mejor remuneración y mejor trabajo

En la encuesta aplicada, se solicitó a los egresados que puntúen de 1 (muy bajo) a 7 (muy bueno) en cuanto a la opción de optar a una mejor remuneración $\mathrm{v} / \mathrm{s}$ obtener un mejor trabajo de acuerdo al área de especialización entre las que se consideraron las siguientes: Auditoría, Contabilidad Avanzada, Tributación, Recursos Humanos, Tecnologías de la Información, Finanzas, Costos, Administración y Gestión.
$\mathrm{Al}$ analizar la relación entre mejor remuneración y mejor trabaja al que opta el egresado de Contador Auditor., se puede observar que existe similares tendencias (véase gráfico 3 ). De todas formas se observa lo siguiente:

- Las áreas con mayor valoración son "Tributaria", "Contabilidad Avanzada" y "Auditoría"

- Las de menor valoración son "Recursos Humanos", "Tecnologías de Información" y "Costos". 


\section{Gráfico 3: “COMPARATIVA ENTRE OPCIÓN A MEJOR REMUNERACIÓN V/S MEJOR TRABAJO"}

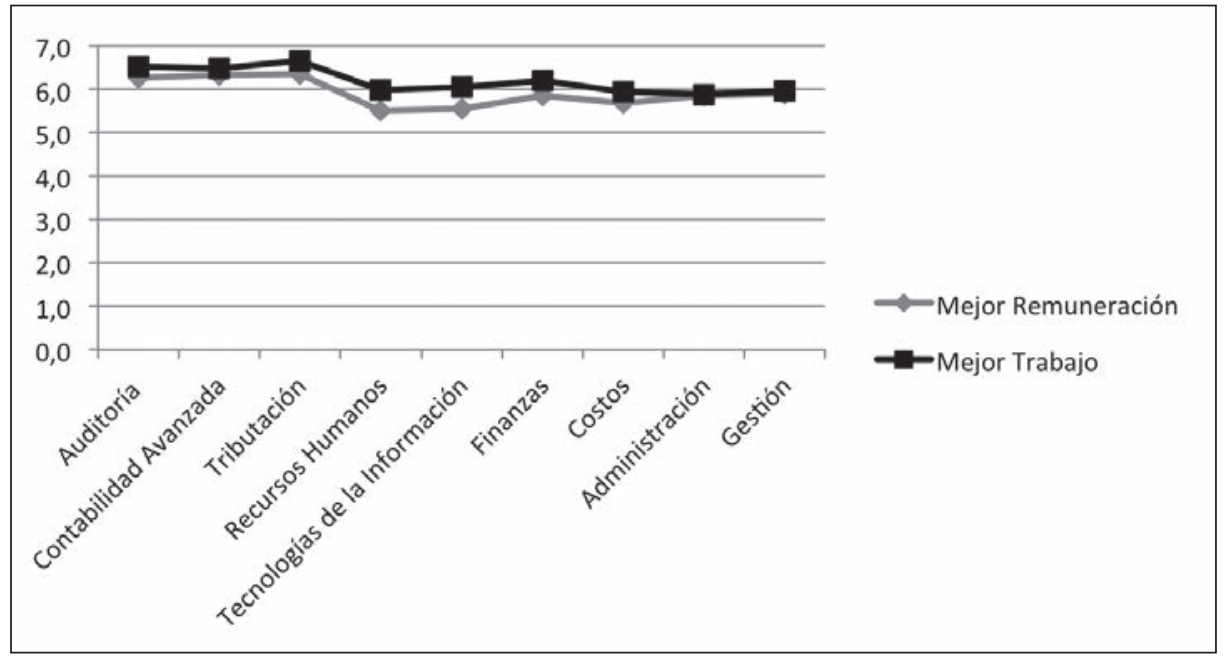

Fuente: Elaboración Propia, año 2015.

\section{Progresión Económica}

Se realizó una análisis respecto de la progresión socio económica de los alumnos identificando 2 variables: Primero el nivel socio económico en el que se clasifican y Segundo la progresión económica después de sus estudios. Respecto de la primera variable (Ver Tabla $\mathrm{N}^{\circ} 4$ ), se observa que el $90 \%$ de los egresados se clasifica en los estratos $\mathrm{C} 2$ y $\mathrm{C} 3$.

Tabla IV: “NIVEL SOCIO ECONÓMICO”

\begin{tabular}{|c|c|}
\hline Nivel Socio Económico & $\%$ \\
\hline ABC1 & $2 \%$ \\
\hline C2 & $45 \%$ \\
\hline C3 & $45 \%$ \\
\hline D & $7 \%$ \\
\hline E & $0 \%$ \\
\hline
\end{tabular}

Fuente: Elaboración Propia año 2015.

Respecto de la segunda variable, se observó que el $44 \%$ de los egresados mantenía el mismo Nivel Socio Económico, 47\% aumentaba un nivel y el 8\% aumentaba dos niveles, dándose sólo un $1 \%$ de retroceso de nivel socio económico.

\section{Desempleo}

Respecto de los egresados desempleados, estos representaron el $12 \%$ de la muestra. Las principales razones del desempleo fueron "Maternidad y Familia", "Continuidad de estudios", es decir más bien razones de población inactiva. A este grupo se les solicitó que valorarán con puntuación de 1 (nada de importante) a 7 (muy importante), las dificultades para encontrar empleo, lo cual arrojó los siguientes resultados (Ver Tabla N`5): 
Tabla V: “DIFICULTAD PARA ENCONTRAR EMPLEO”

\begin{tabular}{|l|c|}
\hline Dificultad & Nota \\
\hline Carencia en la formación universitaria recibida & 3,1 \\
\hline Actividades personales que te impiden trabajar & 3,9 \\
\hline Falta de práctica profesional & 2,9 \\
\hline Exigencia de tener un trabajo que me guste & 4,6 \\
\hline Falta de conocimiento del mercado laboral & 4,4 \\
\hline Exigencia de tener un trabajo bien remunerado & 4,6 \\
\hline Falta de conocimiento de idiomas & 3,1 \\
\hline Falta de conocimiento de Informática & 3,4 \\
\hline La formación global de la universidad & 3,8 \\
\hline
\end{tabular}

Fuente: Elaboración Propia, año 2015.

Como se puede observar las con mayor puntuación son las exigencias de tener un trabajo que me guste y bien remunerado, es decir un convencimiento personal más que razones de mercado.

\section{CONCLUSIÓN}

En esta investigación se pudo identificar cuáles son las competencias más valoradas en el mercado para los Contadores Auditores recientemente egresados, además se pudo analizar su nivel de remuneraciones y su valoración de la calidad del trabajo. Los resultados, evidencian que los egresados participan de la cultura de las competencias y son capaces de discriminar con un elevado grado de precisión el nivel de adquisición y dominio de las competencias sobre las que se les inquiere. Asimismo, tienen una capacidad crítica acerca de los desajustes entre su formación y las necesidades profesionales.

Cuando se aborda el estudio de las competencias desde la perspectiva de los empleadores o mediante el análisis de las ofertas de trabajo, se enriquece considerablemente la comprensión de las competencias. Realizar el esfuerzo de analizar las competencias de forma integral es indispensable, dada su importancia y correlación con la inserción laboral, como se ha detectado en el estudio piloto.

Los resultados obtenidos, permiten visualizar una valoración destacada, dentro de los factores de contratación a la formación global de la Universidad, así como, a la capacidad de trabajar en grupo.

En cuanto a la remuneración se evidenció para cada una de las cohortes estudiadas, valores descendidos respecto de la media nacional. Esta situación puede verse influida por el nivel socioeconómico inicial de los egresados y el ascenso evidenciado. Presentan niveles de ingresos, significativamente superiores, los obtenidos, en primer lugar, quienes se desempeñan realizando asesoría y en segundo lugar, aquellos que trabajan en empresas del rubro minero. Así mismo, se pudo observar, mayores ingresos obtenidos por quienes se desempeñan en el área de recursos humanos, seguido por tributaria y finanzas, siendo del área contable, quienes reciben las remuneraciones más bajas.

En lo referente a la percepción de calidad del trabajo, considerando aspectos, como horarios, ambiente laboral, capacidad de promoción, entre otros, se destaca, quienes trabajan en el área de la tributación y empresas auditoras.

La información presentada de los factores de empleabilidad, pueden transformarse un insumo útil, para la orientación de nuevos planes y programas de estudios, que estén acorde con las necesidades de mercado en función de la valoración otorgada, en coherencia con el paradigma actual de la educación superior.

En consideración a una de las funciones y obligaciones de las instituciones de educación superior, que es el la de preparar estudiantes para un mercado de trabajo específico, que requiere educación formal avanzada, con competencias y cualificación profesional para responder a las demandas presentadas y así conseguir mayor y mejor empleabilidad. Por consiguiente resulta necesario e indispensable, conocer dichas demandas, así como adaptarse a los nuevos requerimientos establecidos por los cambios 
frecuentes en los escenarios. Para los programas asociados a la auditoría, en la Comuna de la Serena, estos en la actualidad y de acuerdo a la percepción de profesionales egresados de éstas carreras, se debería fortalecer las áreas de Recursos Humanos, Finanzas, así como las competencias para el desarrollo de asistencia técnica y desempeño en sectores económicos específicos como minería y sector público, adicionales a las tradicionalmente fortalecidas, como contabilidad, tributaria y administración.

\section{BIBLIOGRAFIA}

Ayats, J.C. Zamora, P. Desantes, R., (2015) La Empleabilidad de los Titulados como Pilar Básico del Espacio Europeo de la Educación Superior, XIII CUIEET, Maspalomas (Gran Canaria).

Barraycoa Martínez, J. y Lasaga Millet, O., (2010), Competencias e inserción laboral: un análisis de la empleabilidad en los recién licenciados en Ade y Economía. Madrid: CEU Ediciones.

Ducci, María Angélica (1996). “El enfoque de competencia laboral en la perspectiva internacional", en Formación basada en competencia laboral. Situación actual y perspectivas. Seminario Internacional, OIT/CINTERFOR/CONOCER. Guanajuato 23-25 de mayo, pp.15-26.

Espacio Europeo de Enseñanza Superior. Declaración conjunta de los Ministros europeos de enseñanza. Declaración de Bologna. Italia, 1999.

González, E. Alfaro, M. Cortés, P. Hernández S. (2012), “Competencias requeridas por el contador auditor, en función a los cambios experimentados por la profesión", CAPIC REVIEW Vol. 10 (1): 53-62, 2012.

Kinnear, Thomas y Taylor, James, (2010) Investigación de Mercados, México, McGraw-Hill, 1993.

Lasaga, O. y Barrycoa, J. (2010); "Competencias profesionales y empleabilidad: la inserción laboral de los licenciados en publicidad y RR.PP"; Universitat Abat Oliba Ceu"; Madrid: CEU Ediciones.

Marques, J. (2001). “Nuevas tendencias en la auditoría", Octubre-Diciembre, Contaduría y Administración $\mathrm{N}^{\circ} 203$, 37- 44. 


\section{ABSTRACT}

Among the objectives formulated in the Bologna Declaration (1999), and in this case, been axis on which the new educational paradigm in higher education is based, it is: "Develop academic, competence and professional qualification criteria to answer the labor market demand the and let respond to the current educational, labor and social challenges". The Berlin Conference (2003), emphasizes the employability of graduates. The Bergen Conference (2005), points out that to improve the employability of graduates, it is necessary to strengthen the dialogue between employers and social agents.

Following the constant changes generated in the profession and the need to adapt to them permanently constant evaluation of the skills and knowledge of professionals in the area of the audit is necessary. This research makes an analysis of the evaluation of the demands of market, professional skills for employment and remuneration of the graduates from the Accountancy program in the city of La Serena, in order to provide updated information on employability factors, as useful input to the orientation of the study programs, mobilizing the brainpower and aligning it to what socio-economic actors demand.

The study sets a mixed perspective. The qualitative trait manifests by obtaining information of the graduates of audit considered like strategic actors, in this case graduates by subjective perceptions and visions that those delivered, while the quantity is expressed in terms of the analysis of data obtained by implementing an insertion surveym l'Agència per a la Qualitat from the System of University of Catalonia (AQU).

The investigation allowed to identify the most valued skills according to the market for recent graduates of Accountancy, and provide the confirmation of the importance of personal characteristics, as a factor in employability. It was determined the existence of a relationship between skills, performance category and level of remuneration, same as the determination of the assessing on quality of work.

Keywords: Employability, Job Placement, Professional skills.

\section{INTRODUCCIÓN}

En un entorno global y competitivo, cada vez más demandante de prácticas eficientes, como actual, surge la necesidad de contar con profesionales capaces de responder a requerimientos de control y revisión continua de procesos y actividades que se ejecutan en los diversas tipos empresas y organizaciones, tanto privadas como gubernamentales.

En las últimas décadas la marcada y constante evolución de la auditoría ha provocado que el auditor no se desempeñe como profesional con un enfoque holístico sino más bien se ha marcado la especialización de este tanto en los aspectos personales, como el las competencias profesionales (Marques 2001).

El profesional de la auditoría desde sus orígenes ha sido vinculado casi en exclusividad a desempeñarse en lo relacionado a preparación, análisis, revisión y validación de estados financieros, de hecho en los orígenes de la profesión se limitaba a la mera vigilancia con la finalidad de evitar fraudes y errores. Luego con el crecimiento de las empresas y la separación de la propiedad de la administración, se hizo necesario garantizar (Marques 2001), la información económica financiera de las organizaciones. En Gran Bretaña, debido a las quiebras que se produjeron durante la revolución industrial, se desarrolló la auditoría para generar confianza en los inversores, cuestión que no tardó en extenderse a otros países. Posteriormente las crisis de Wall Strett de 1929 y las sucesivas crisis hasta hoy, han fortalecido a la profesión tanto del punto de vista ético, técnico, legislativo y de investigación.

De acuerdo al enfoque anterior, los cambios que ha experimentado y sigue experimentando el profesional de la auditoría, lo ha llevado a desempeñarse en distintas áreas, lo que genera diferencias socio-laborales, expresadas en empleabilidad, calidad de empleo y remuneraciones.

La evidencia, demuestra que los profesionales de la Auditoría, egresados de Instituciones de educación superior de la comuna de La Serena, experimentan una significativa variabilidad en los aspectos antes señalado, lo cual hace necesario estudia las causales que generan estas 
diferencias. De esta manera surgen las siguientes interrogantes:

- ¿Existen diferencias en la calidad de empleo y las remuneraciones de los egresados de la carrera de auditoría, en función del área de desempeño en la que se desenvuelven?

- ¿Las competencias profesionales del egresado de carreras de auditoría de la ciudad de La Serena, condicionan la calidad de empleo y su remuneración?

\section{Objetivo general}

Analizar la Valoración a las demandas de mercado, de las competencias profesionales para la inserción laboral y remuneración de los titulados de la carrera de auditoría, en la actualidad para la comuna de La Serena.

\section{Objetivos específicos}

- Analizar situación socio-laboral de los egresados de carreras de Auditoría

- Identificar competencias profesionales requeridas para el egresado de las carreras de Auditoría en la actualidad,

- Describir la relación entre competencias profesionales, empleabilidad y remuneración, a través de relación causa efecto.

\section{Hipótesis}

$\mathrm{H}_{\mathrm{A}}$ : La empleabilidad, remuneraciones y calidad de empleo de los egresados de la carrera de $\mathrm{Au}$ ditoría, está determinada por las competencias profesionales que posea el egresado.

\section{Metodología}

La metodología de la investigación ha sido por siempre el sustento empírico de todo estudio. El cómo se llevará a cabo la investigación y el perfil al que esta responde, son aspectos relevantes de considerar. Tomando en consideración lo anterior, es posible señalar que el presente estudio se enmarca dentro de un diseño no experimental, puesto que se estudia el fenómeno bajo sus condiciones naturales y no se realiza manipulación de las variables, ya que al hacerlo se estarían sesgando los datos al momento de analizarlos.

Con respecto al enfoque, el estudio configura una perspectiva mixta (Hernández 2003). Perspectiva en que se fusionan elementos tanto del área cualitativa como cuantitativa. El rasgo cua- litativo se manifiesta en la obtención de información de agentes estratégicos, en este caso los egresados, mediante las percepciones y visiones subjetivas que estos nos entregan, mientras que lo cuantitativo se expresa en función del análisis de los datos obtenidos en el instrumento aplicado.

Con respecto al tipo de investigación, la metodología utilizada fue inicialmente de carácter exploratorio, para continuar con un estudio de tipo descriptivo. En primer lugar se identifica las competencias profesionales requeridas por el mercado, para el egresado de las carreras de $\mathrm{Au}$ ditoría en la actualidad, en base a información bibliográfica y documental. En segundo lugar se analizó la situación socio laboral de los egresados de las carreras de Auditoría, de instituciones de educación superior de la ciudad de La Serena, analizando aspectos tales como: La situación laboral actual, el acceso al primer empleo, la satisfacción con el trabajo actual, la valoración de los factores de contratación, la remuneración obtenida, la adecuación de la formación recibida al empleo ocupado, la formación continuada, la movilidad, el rendimiento académico y status económico, así como, las acciones emprendidas en caso de estar actualmente desempleado. Para ello se aplicó, como base, entre enero y mayo del año 2015 la encuesta de inserción de l'Agència per a la Qualitat del Sistema Universitari de Catalunya (AQU 2008) por tratarse de un instrumento estadísticamente y sociológicamente validado y utilizado en un estudio similar llamado "Competencias profesionales y empleabilidad: la inserción laboral de los licenciados en publicidad y RR.PP. de la Universitat Abat Oliba Ceu", de las autores Lasaga y Barraycoa 2010.

Siguiendo el esquema de Kinnear y Taylor (1993), los pasos para definir la muestra fueron los siguientes:

\section{a. Población:}

i. Alcance: Instituciones de Educación superior de la Ciudad de La Serena, que cuenten con egresados durante los 4 últimos años.

ii. Tiempo: egresados entre 2011 y 2014.

iii. Elementos: Egresados de instituciones de educación superior de la carrera de Auditoría.

iv. Unidades de muestreo: Todos los egresados de instituciones de educación superior de la carrera de Auditoría, alcanzan un total 324 egresados. 
a. Marco muestral: En concordancia con las restricciones establecidas para la población, los sujetos objeto de estudio, pertenecen solamente a la Universidad de La Serena y a Inacap.

b. Tamaño de la muestra: El estudio se aplicó a 158 egresados de las instituciones señaladas.

c. Procedimiento de muestreo: Se utilizó un muestreo no probabilístico por conveniencia, en función de la accesibilidad de los sujetos para los investigadores.

El trabajo de campo se desarrolló considerando como fuente de información primaria, la aplicación de la encuesta, esta se aplicó a los sujetos de la muestra, en formato papel, así como en formato digital a través de un portal en internet. Como fuente secundaria se utilizó bibliografía relacionada con empleabilidad y competencias, así como las declaraciones y escritos emanados en conferencias como la de Bolonia (1999), la Conferencia de Berlín (2003), la Conferencia de Bergen (2005), entre otros. El procesamiento y análisis de resultados se realizó utilizando herramientas como el diagrama causa efecto, así como el uso de software para determinación de tendencia central y dispersión.

\section{Exposición de Resultados:}

Entre Enero y Mayo del año 2015 se aplicó una encuesta a 158 egresados, entre los años 2011 y 2014, de las carreras de auditoría de la Universidad de La Serena y de INACAP, por ser los programas cumplen con la restricción de tener egresados en los 4 últimos años. En esta encuesta de consultó sobre la situación laboral actual, el acceso al primer empleo, la satisfacción con el trabajo actual, la valoración de los factores de contratación, la remuneración obtenida, la adecuación de la formación recibida al empleo ocupado, la formación continuada, la movilidad, el rendimiento académico, el status económico y acciones emprendidas en caso de estar titulado.

Una vez obtenidos los resultados se procedió a su procesamiento y análisis, utilizando herramientas de análisis, como el diagrama causa efecto y software para determinación de tendencias. Obteniendo los siguientes resultados.

\section{Valoración de los factores de Contratación.}

La selección de personal en las empresas es una variable esencial para valorar la incidencia de la formación en competencias en la inserción laboral. Por lo cual se solicitó a los encuestados una ponderación sobre los factores que han determinado su inserción laboral, Los resultados muestran que las competencias personales son las que tienen mayor valoración (Ver Gráfico 1) Destacando variables como "la manera de ser" y "la capacidad de trabajar en grupos", y sólo destaca una variable que no tiene que ver con la competencia personal que es "la formación Global en la Universidad". Se deduce entonces que la clave del éxito de un proceso de selección "radica en las competencias personales y sociales, tanto si se tienen como si se demuestra la capacidad para desarrollarlas". ${ }^{3}$

Por otra parte los conocimientos teóricos e instrumentales, alcanzan una puntuación baja, dada la percepción de los egresados que a medida que adquieren experiencia profesional lo teórico y lo instrumental se adquiere fácilmente. Además en esta carrera en particular el avance de las normas y la teoría es muy rápido, por lo cual una parte de la formación de hoy puede quedar obsoleta mañana. Por ello más que conocimientos teóricos, las empresas aprecian, como una cualidad personal importante, la capacidad de aprendizaje y adaptación.

3 BARRAYCOA MARTÍNEZ, J. y LASAGA MILLET, O., Competencias e inserción laboral: un análisis de la empleabilidad en los recién licenciados en Ade y Economía. Madrid: CEU Ediciones, 2009, pág. 134. 


\section{Gráfico 1: "VALORACIÓN DE LOS FACTORES DE CONTRATACIÓN"}

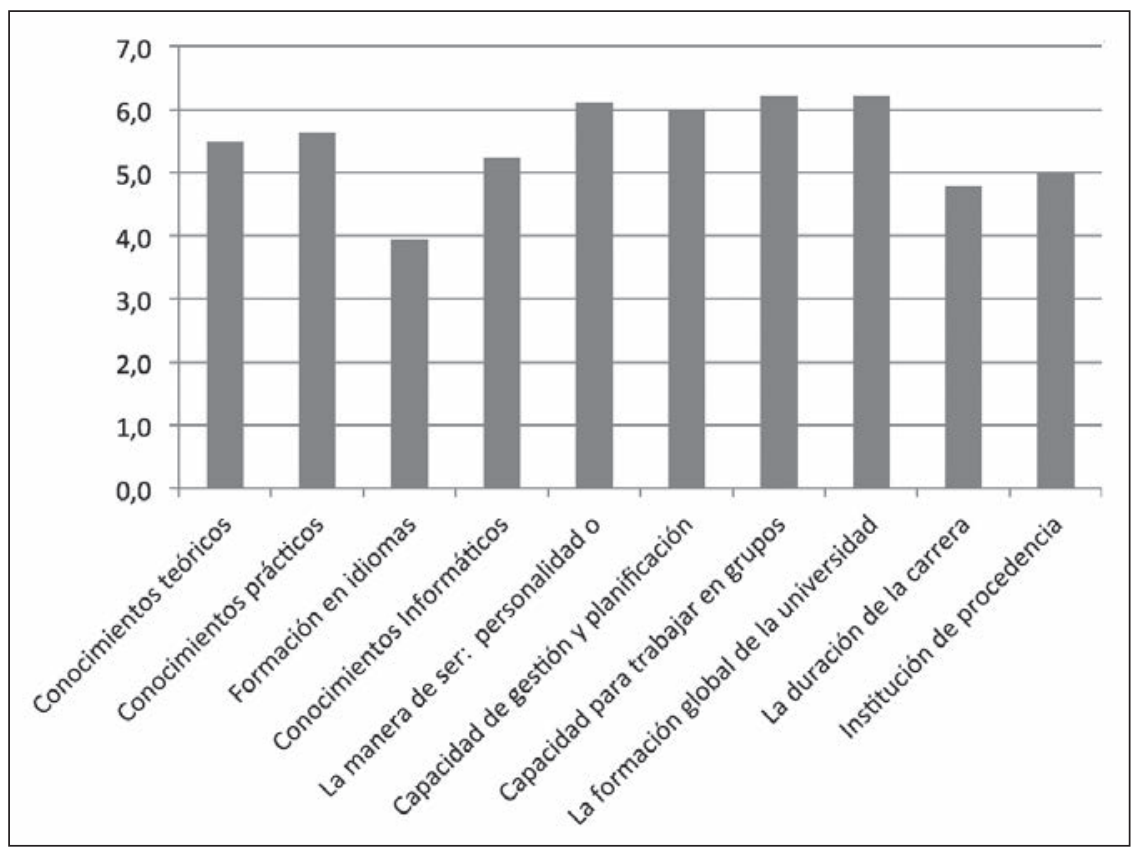

Fuente: Elaboración Propia año 2015.

2. Competencias Transversales: Comparativo entre los conocimientos adquiridos en la universidad $v / s$ su utilidad en el trabajo.

En la encuesta aplicada, se solicitó a los egresados que puntúen de 1 (muy bajo) a 7 (muy bueno) el nivel que adquirieron en la Universidad y su adecuación para el desempeño de su trabajo respecto a diversos aspectos relacionados tanto con la formación como con las competencias:

- Conocimientos teóricos

- Formación práctica

- Competencias instrumentales: informática e idiomas.

- Competencias sociales: trabajo en equipo y comunicación tanto oral como escrita.

- Competencias personales: liderazgo, gestión, resolución de problemas, toma de decisiones, creatividad y pensamiento crítico.
$\mathrm{Al}$ analizar la relación entre la formación en conocimientos y competencias adquirida a lo largo de los estudios de Contador Auditor. y su utilidad en el empleo, destaca que se mantienen las tendencias de opinión (véase gráfico 2). De todas formas se observa lo siguiente:

- La Valoración de las competencias es pareja, es decir no hay grandes diferencias de puntuación

- Las Competencias Instrumentales (Informática e idiomas), son las menos valoradas.

- Se han adquirido en el grado adecuado para el empleo: entre ellas están la expresión oral y escrita, el liderazgo, la resolución de problemas, la creatividad, el pensamiento crítico y los idiomas.

- La competencia social más valorada es el "trabajo en equipo".

- Y en las competencias personales destaca la "resolución de problemas"

- Además se valora más la competencia en la aplicación en el trabajo. 
Gráfico 2: “COMPARATIVA ENTRE EL NIVEL DE COMPETENCIAS ADQUIRIDO EN LA UNIVERSIDAD Y EL REQUERIDO PARA EL DESEMPEÑO DEL PUESTO DE TRABAJO”

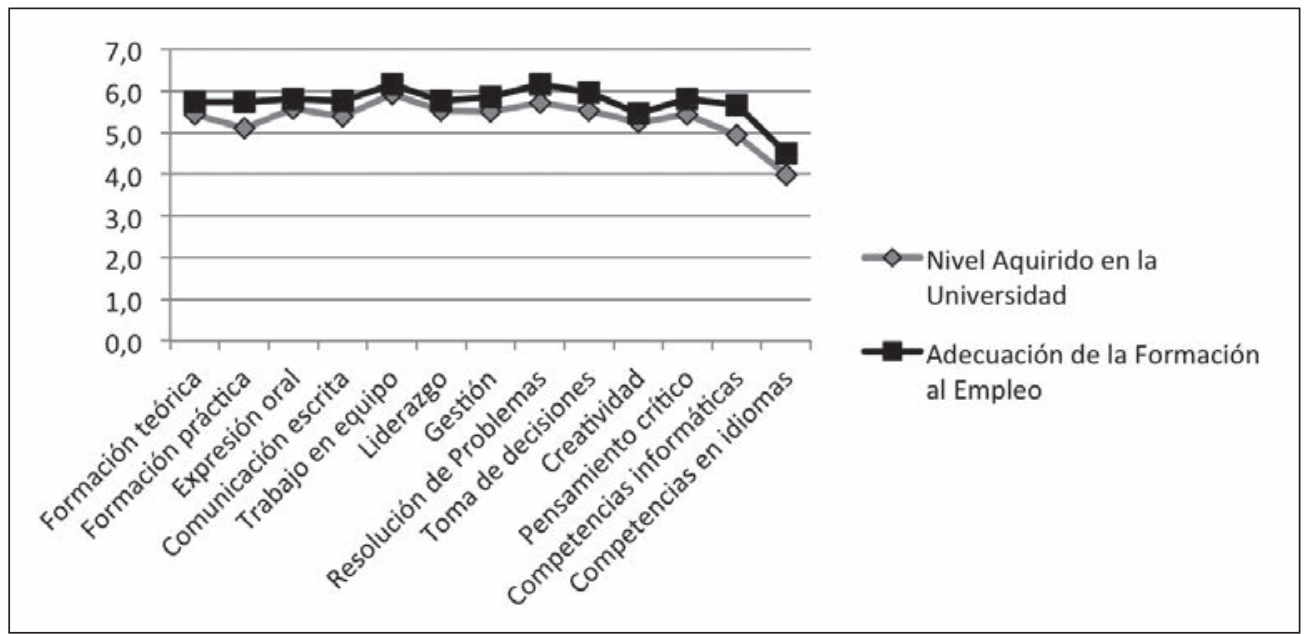

Fuente: Elaboración Propia año 2015.

\section{Sueldos.}

El sueldo bruto promedio en los egresados de la carrera de Auditoría entre los años 2011 y 2014 de la ciudad de La Serena es de \$714.768, registrándose el mayor sueldo por un monto bruto de $\$ 1.970 .000$ de un egresado que trabaja en el área de Recursos Humanos en el rubro de la minería, y el menor sueldo de $\$ 310.000$ corres- ponde a un egresado que trabaja como analista contable en una empresa de asesorías contables.

Se realizó un comparativo entre los sueldos brutos promedio según año de egreso y los datos entregados por el sitio Mi futuro.cl ${ }^{4}$, en el cual se puede ver que los egresados de la Ciudad de la Serena están por debajo de los promedios Nacionales

Tabla I: "COMPARATIVO ENTRE SUELDOS NACIONALES V/S CIUDAD DE LA SERENA"

\begin{tabular}{|l|c|c|}
\hline Años de Egreso & $\begin{array}{c}\text { Sueldo Promedio } \\
\text { según encuesta }\end{array}$ & $\begin{array}{c}\text { Sueldo } \\
\text { Promedio, según } \\
\text { mifuturo.cl }\end{array}$ \\
\hline Egresados 2011 & 984.152 & 1.132 .154 \\
\hline Egresados 2012 & 710.892 & 1.041 .866 \\
\hline Egresados 2013 & 634.926 & 941.312 \\
\hline Egresados 2014 & 596.152 & 855.901 \\
\hline
\end{tabular}

Fuente: Elaboración Propia, año 2015.

También se efectuó un análisis respecto de los sueldos según la actividad económica en la que desenvuelven los egresados (Ver tabla $\mathrm{N}^{\circ} 2$ ), en donde se observó que las actividades que en- tregan mejor remuneración son las "asesorías" y el sector de "la minería" y la remuneración más baja está en los "servicios contables". 
Tabla II: "REMUNERACIÓN SEGÚN ACTIVIDAD ECONÓMICA"

\begin{tabular}{|l|c|r|}
\hline \multicolumn{1}{|c|}{ Actividad Económica } & Sueldos Promedio & \multicolumn{1}{c|}{$\%$} \\
\hline Auditoría & 796.587 & $21 \%$ \\
\hline Servicios Contables & 493.467 & $14 \%$ \\
\hline Minería & 841.862 & $13 \%$ \\
\hline Inmobiliario & 622.113 & $5 \%$ \\
\hline Salud & 476.872 & $5 \%$ \\
\hline Servicio Público & 760.711 & $5 \%$ \\
\hline Asesorías & 1.031 .200 & $5 \%$ \\
\hline Portuaria & 672.500 & $4 \%$ \\
\hline Educación & 650.585 & $4 \%$ \\
\hline Otros & 688.844 & $27 \%$ \\
\hline
\end{tabular}

Fuente: Elaboración Propia año 2015.

En el análisis de las remuneraciones, se analizó también el nivel de sueldo de acuerdo al área de desempeño (Ver Tabla $N^{\circ} 3$ ), destacando las mayores remuneraciones en las áreas de "recursos humanos" y "Finanzas" y la con menor remuneración "Contabilidad".

Tabla III: “REMUNERACIÓN SEGÚN ÁREA DE DESEMPEÑO”

\begin{tabular}{|l|c|r|}
\hline \multicolumn{1}{|c|}{ Aréa de Desempeño } & Sueldos Promedio & \multicolumn{1}{c|}{$\%$} \\
\hline Administración & 731.400 & $9 \%$ \\
\hline Auditoría & 729.368 & $17 \%$ \\
\hline Contabilidad & 632.424 & $39 \%$ \\
\hline Control Interno & 690.926 & $5 \%$ \\
\hline Finanzas & 798.733 & $6 \%$ \\
\hline Recursos Humanos & 960.857 & $3 \%$ \\
\hline Tesorería & 428.121 & $10 \%$ \\
\hline Tributaria & 846.864 & \\
\hline
\end{tabular}

Fuente: Elaboración Propia, año 2015.

4. Valoración del Trabajo: Comparativo entre mejor remuneración y mejor trabajo

En la encuesta aplicada, se solicitó a los egresados que puntúen de 1 (muy bajo) a 7 (muy bueno) en cuanto a la opción de optar a una mejor remuneración $\mathrm{v} / \mathrm{s}$ obtener un mejor trabajo de acuerdo al área de especialización entre las que se consideraron las siguientes: Auditoría, Contabilidad Avanzada, Tributación, Recursos Humanos, Tecnologías de la Información, Finanzas, Costos, Administración y Gestión.
$\mathrm{Al}$ analizar la relación entre mejor remuneración y mejor trabaja al que opta el egresado de Contador Auditor., se puede observar que existe similares tendencias (véase gráfico 3 ). De todas formas se observa lo siguiente:

- Las áreas con mayor valoración son "Tributaria", "Contabilidad Avanzada" y "Auditoría"

- Las de menor valoración son "Recursos Humanos", "Tecnologías de Información" y "Costos". 


\section{Gráfico 3: “COMPARATIVA ENTRE OPCIÓN A MEJOR REMUNERACIÓN V/S MEJOR TRABAJO"}

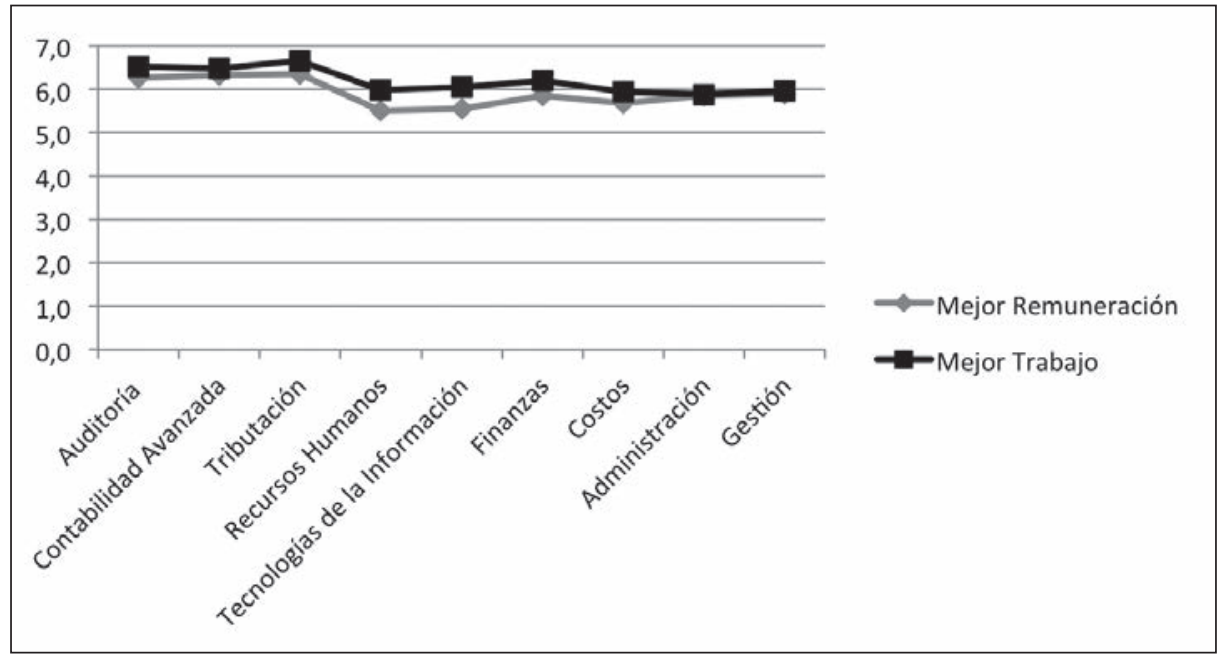

Fuente: Elaboración Propia, año 2015.

\section{Progresión Económica}

Se realizó una análisis respecto de la progresión socio económica de los alumnos identificando 2 variables: Primero el nivel socio económico en el que se clasifican y Segundo la progresión económica después de sus estudios. Respecto de la primera variable (Ver Tabla $\mathrm{N}^{\circ} 4$ ), se observa que el $90 \%$ de los egresados se clasifica en los estratos $\mathrm{C} 2$ y $\mathrm{C} 3$.

Tabla IV: “NIVEL SOCIO ECONÓMICO”

\begin{tabular}{|c|c|}
\hline Nivel Socio Económico & $\%$ \\
\hline ABC1 & $2 \%$ \\
\hline C2 & $45 \%$ \\
\hline C3 & $45 \%$ \\
\hline D & $7 \%$ \\
\hline E & $0 \%$ \\
\hline
\end{tabular}

Fuente: Elaboración Propia año 2015.

Respecto de la segunda variable, se observó que el $44 \%$ de los egresados mantenía el mismo Nivel Socio Económico, 47\% aumentaba un nivel y el 8\% aumentaba dos niveles, dándose sólo un $1 \%$ de retroceso de nivel socio económico.

\section{Desempleo}

Respecto de los egresados desempleados, estos representaron el $12 \%$ de la muestra. Las principales razones del desempleo fueron "Maternidad y Familia", "Continuidad de estudios", es decir más bien razones de población inactiva. A este grupo se les solicitó que valorarán con puntuación de 1 (nada de importante) a 7 (muy importante), las dificultades para encontrar empleo, lo cual arrojó los siguientes resultados (Ver Tabla N`5): 
Tabla V: “DIFICULTAD PARA ENCONTRAR EMPLEO”

\begin{tabular}{|l|c|}
\hline Dificultad & Nota \\
\hline Carencia en la formación universitaria recibida & 3,1 \\
\hline Actividades personales que te impiden trabajar & 3,9 \\
\hline Falta de práctica profesional & 2,9 \\
\hline Exigencia de tener un trabajo que me guste & 4,6 \\
\hline Falta de conocimiento del mercado laboral & 4,4 \\
\hline Exigencia de tener un trabajo bien remunerado & 4,6 \\
\hline Falta de conocimiento de idiomas & 3,1 \\
\hline Falta de conocimiento de Informática & 3,4 \\
\hline La formación global de la universidad & 3,8 \\
\hline
\end{tabular}

Fuente: Elaboración Propia, año 2015.

Como se puede observar las con mayor puntuación son las exigencias de tener un trabajo que me guste y bien remunerado, es decir un convencimiento personal más que razones de mercado.

\section{CONCLUSIÓN}

En esta investigación se pudo identificar cuáles son las competencias más valoradas en el mercado para los Contadores Auditores recientemente egresados, además se pudo analizar su nivel de remuneraciones y su valoración de la calidad del trabajo. Los resultados, evidencian que los egresados participan de la cultura de las competencias y son capaces de discriminar con un elevado grado de precisión el nivel de adquisición y dominio de las competencias sobre las que se les inquiere. Asimismo, tienen una capacidad crítica acerca de los desajustes entre su formación y las necesidades profesionales.

Cuando se aborda el estudio de las competencias desde la perspectiva de los empleadores o mediante el análisis de las ofertas de trabajo, se enriquece considerablemente la comprensión de las competencias. Realizar el esfuerzo de analizar las competencias de forma integral es indispensable, dada su importancia y correlación con la inserción laboral, como se ha detectado en el estudio piloto.

Los resultados obtenidos, permiten visualizar una valoración destacada, dentro de los factores de contratación a la formación global de la Universidad, así como, a la capacidad de trabajar en grupo.

En cuanto a la remuneración se evidenció para cada una de las cohortes estudiadas, valores descendidos respecto de la media nacional. Esta situación puede verse influida por el nivel socioeconómico inicial de los egresados y el ascenso evidenciado. Presentan niveles de ingresos, significativamente superiores, los obtenidos, en primer lugar, quienes se desempeñan realizando asesoría y en segundo lugar, aquellos que trabajan en empresas del rubro minero. Así mismo, se pudo observar, mayores ingresos obtenidos por quienes se desempeñan en el área de recursos humanos, seguido por tributaria y finanzas, siendo del área contable, quienes reciben las remuneraciones más bajas.

En lo referente a la percepción de calidad del trabajo, considerando aspectos, como horarios, ambiente laboral, capacidad de promoción, entre otros, se destaca, quienes trabajan en el área de la tributación y empresas auditoras.

La información presentada de los factores de empleabilidad, pueden transformarse un insumo útil, para la orientación de nuevos planes y programas de estudios, que estén acorde con las necesidades de mercado en función de la valoración otorgada, en coherencia con el paradigma actual de la educación superior.

En consideración a una de las funciones y obligaciones de las instituciones de educación superior, que es el la de preparar estudiantes para un mercado de trabajo específico, que requiere educación formal avanzada, con competencias y cualificación profesional para responder a las demandas presentadas y así conseguir mayor y mejor empleabilidad. Por consiguiente resulta necesario e indispensable, conocer dichas demandas, así como adaptarse a los nuevos requerimientos establecidos por los cambios 
frecuentes en los escenarios. Para los programas asociados a la auditoría, en la Comuna de la Serena, estos en la actualidad y de acuerdo a la percepción de profesionales egresados de éstas carreras, se debería fortalecer las áreas de Recursos Humanos, Finanzas, así como las competencias para el desarrollo de asistencia técnica y desempeño en sectores económicos específicos como minería y sector público, adicionales a las tradicionalmente fortalecidas, como contabilidad, tributaria y administración.

\section{BIBLIOGRAFIA}

Ayats, J.C. Zamora, P. Desantes, R., (2015) La Empleabilidad de los Titulados como Pilar Básico del Espacio Europeo de la Educación Superior, XIII CUIEET, Maspalomas (Gran Canaria).

Barraycoa Martínez, J. y Lasaga Millet, O., (2010), Competencias e inserción laboral: un análisis de la empleabilidad en los recién licenciados en Ade y Economía. Madrid: CEU Ediciones.

Ducci, María Angélica (1996). “El enfoque de competencia laboral en la perspectiva internacional", en Formación basada en competencia laboral. Situación actual y perspectivas. Seminario Internacional, OIT/CINTERFOR/CONOCER. Guanajuato 23-25 de mayo, pp.15-26.

Espacio Europeo de Enseñanza Superior. Declaración conjunta de los Ministros europeos de enseñanza. Declaración de Bologna. Italia, 1999.

González, E. Alfaro, M. Cortés, P. Hernández S. (2012), “Competencias requeridas por el contador auditor, en función a los cambios experimentados por la profesión", CAPIC REVIEW Vol. 10 (1): 53-62, 2012.

Kinnear, Thomas y Taylor, James, (2010) Investigación de Mercados, México, McGraw-Hill, 1993.

Lasaga, O. y Barrycoa, J. (2010); "Competencias profesionales y empleabilidad: la inserción laboral de los licenciados en publicidad y RR.PP"; Universitat Abat Oliba Ceu"; Madrid: CEU Ediciones.

Marques, J. (2001). “Nuevas tendencias en la auditoría", Octubre-Diciembre, Contaduría y Administración $\mathrm{N}^{\circ} 203$, 37- 44. 